Aus der Abteilung Neurologie

(Prof. Dr. med. Bähr)

im Zentrum Neurologische Medizin

der Medizinischen Fakultät der Universität Göttingen

\title{
DIE WIRKUNG EINES RGMa-ANTIKÖRPERS IM OPTIKUSNEURITIS-MODELL
}

\author{
INAUGURAL - DISSERTATION \\ zur Erlangung des Doktorgrades \\ der Medizinischen Fakultät der \\ Georg-August-Universität zu Göttingen \\ vorgelegt von \\ Sophia Susanna Scheumann \\ aus \\ Bühl
}

Göttingen 2010 
Dekan: Prof. Dr. med. C. Frömmel

I. Berichterstatterin: PD Dr. med. M. Sättler

II. Berichterstatter/in:

III. Berichterstatter/in:

Tag der mündlichen Prüfung: 


\section{INHALTSVERZEICHNIS}

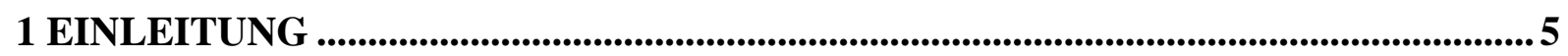

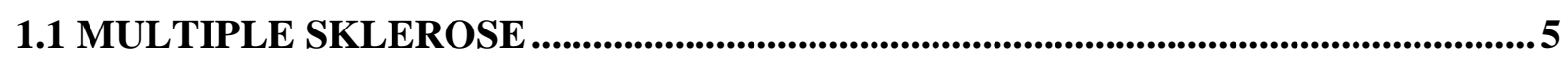

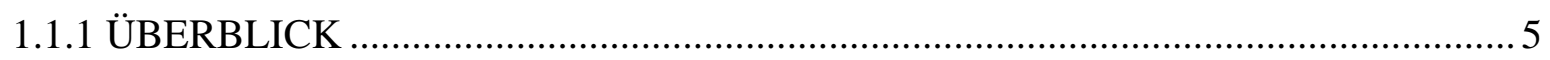

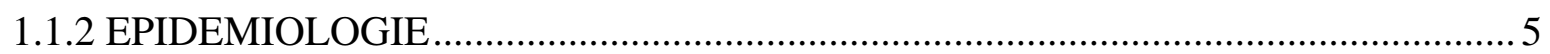

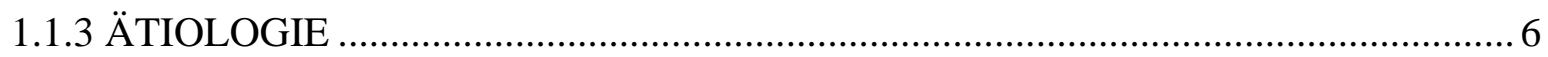

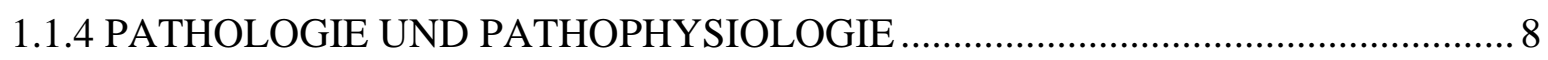

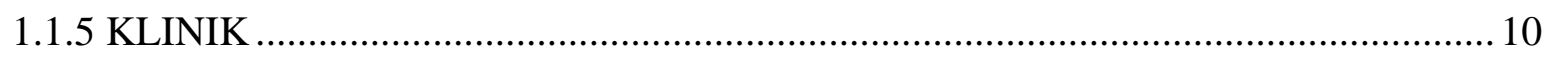

1.1.6 THERAPIE

1.2 TIERMODELLE DER MULTIPLEN SKLEROSE ....................................................12

1.2.1 EXPERIMENTELLE AUTOIMMUNE ENZEPHALOMYELITIS (EAE) ............... 12

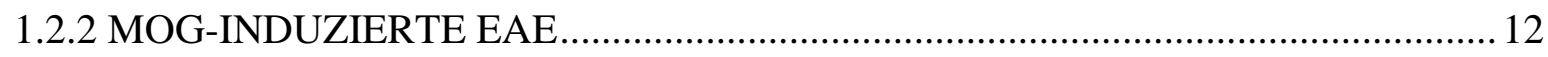

1.3 LENKMOLEKÜLE (,GUIDANCE MOLECULES“) )...................................................... 14

1.3.1 AXONREGENERATIONS-HEMMENDE LENKMOLEKÜLE .............................. 14

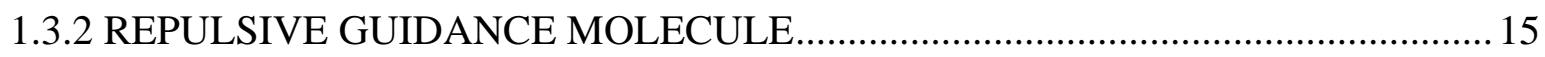

1.4 ZIELSETZUNG DER ARBEIT ..............................................................................18

2 MATERIAL UND METHODEN ..................................................................................... 19

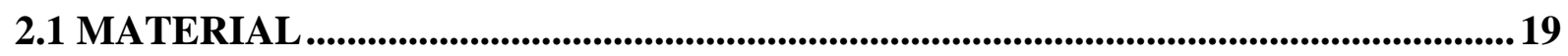

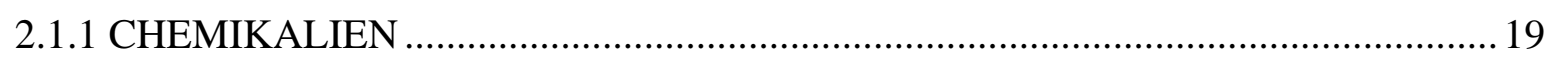

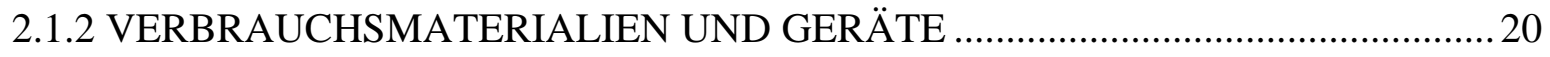

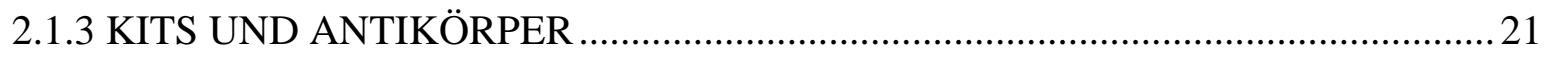

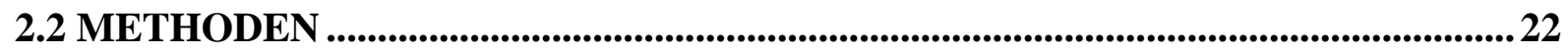

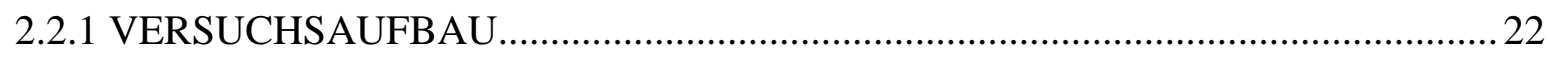

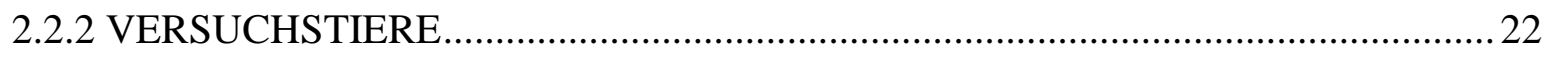

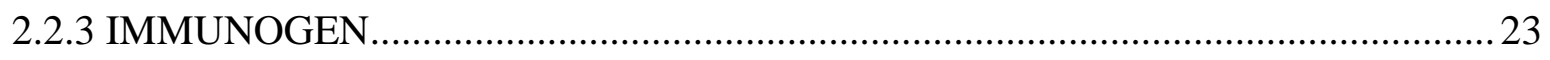

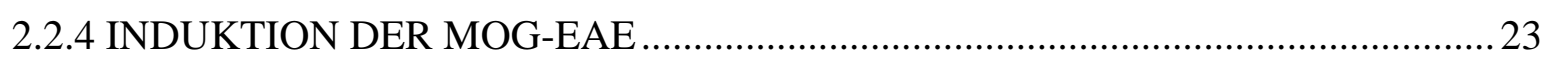

2.2.5 STEREOTAKTISCHE COLLICULUS-INJEKTION ………………………….......2 23

2.2.6 BEHANDLUNG DER TIERE MIT $\alpha$-RGMA ( $\alpha$-RGMA, $\alpha$-HRGMA, PBS) .......... 24

2.2.7 BEURTEILUNG DER KLINIK DER TIERE UNTER $\alpha$-RGMA-BEHANDLUNG 24

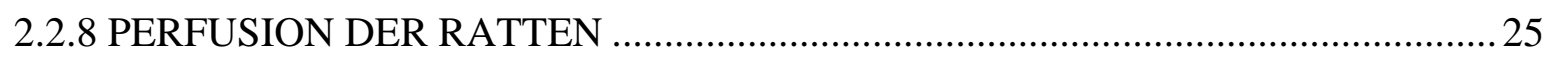

2.2.9 GEWEBEENTNAHME, FIXATION UND HERSTELLUNG DER

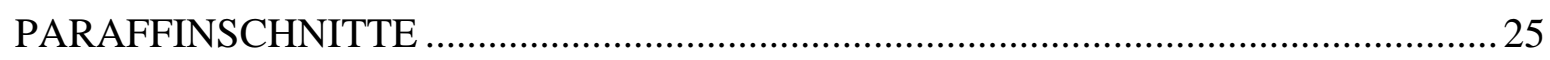

2.2.10 AUSWERTUNG DER DICHTE DER RETINALEN GANGLIENZELLEN .........25 


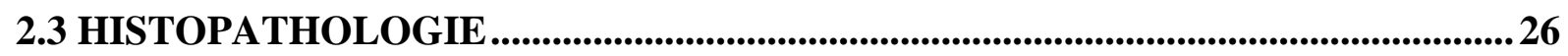

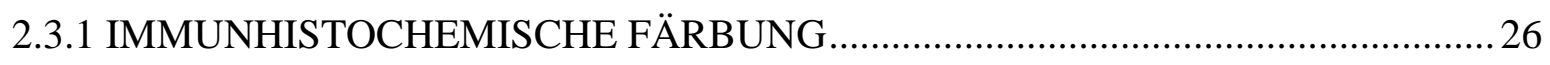

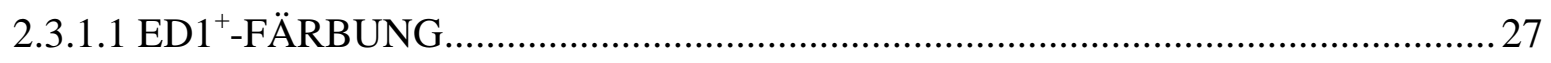

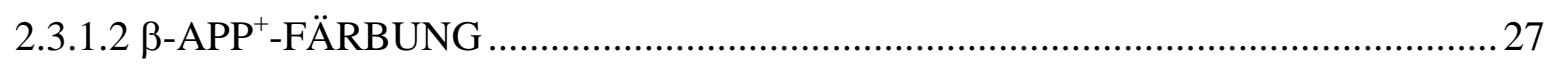

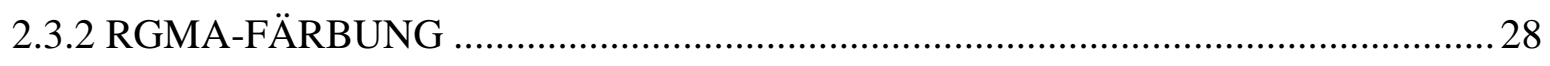

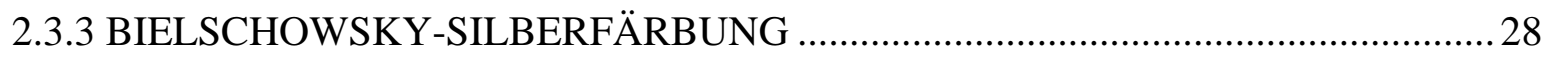

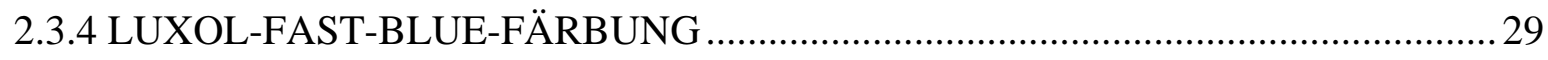

2.4 STATISTISCHE ANALYSEN.........................................................................................29

3 ERGEBNISSE ..............................................................................................................................31

3.1 RGMA-EXPRESSION IM ZNS ......................................................................................31

3.2 KLINISCHE BEURTEILUNG DER $\alpha$-RGMA-BEHANDLUNG................................34

3.3 EINFLUSS DER $\alpha$-RGMA-BEHANDLUNG AUF DIE RGZ ....................................337

3.4 HISTOPATHOLOGIE DER SEHNERVEN UNTER $\alpha$-RGMA-BEHANDLUNG ..39

4 DISKUSSION .................................................................................................................................... 43

4.1 EVALUATION DES MOG-INDUZIERTEN EAE-MODELLS...................................... 43

4.2 THERAPIEN MIT MONOKLONALEN ANTIKÖRPERN ............................................ 46

4.3 NEUROPROTEKTIVE ERGÄNZUNGSBEHANDLUNGEN .......................................48

4.4 DIE ANTIKÖRPER-GETRIGGERTE ANTAGONISIERUNG VON RGMA- EINE POTENTE, INNOVATIVE BEHANDLUNGSSTRATEGIE DER MS? ...........................50

5 ZUSAMMENFASSUNG _......................................................................................................53

6 ANHANG: ABKÜRZUNGEN UND EINHEITEN ..............................................................55

7 LITERATURVERZEICHNIS ...................................................................................57 


\section{EINLEITUNG}

\subsection{MULTIPLE SKLEROSE}

\subsection{1 ÜBERBLICK}

Die Multiple Sklerose (MS) ist eine chronisch entzündliche Entmarkungserkrankung des Zentralen Nervensystems (ZNS). Erstmalig umfassend wurde das Krankheitsbild von Jean Martin Charcot 1868 beschrieben. Er verwies auf die klassische Symptomtrias Nystagmus, Intentionstremor und skandierende Sprache, dabei vermutete er bereits einen Markscheidenverlust als Ursache der Symptome. Mittlerweile wird eine weitaus größere Anzahl an Symptomen der Erkrankung zugeschrieben. Ihren pathogenetischen Ursprung haben diese in entzündlichen Läsionen in unterschiedlichsten Regionen des ZNS. Die zugrunde liegende Entzündung ist von einem diskontinuierlichen Zerfall der Myelinscheiden und zusätzlich von axonalem und neuronalem Schaden begleitet. Dabei ist die Destruktion der Nervenzellen aufgrund ihrer Irreversibilität von besonderer Bedeutung. Während die antiinflammatorische Therapie und Schubprophylaxe in den letzten Jahren eine enorme Weiterentwicklung erfahren haben, bleibt ein zufriedenstellender Therapieansatz chronisch progredienten Verläufe, die hauptsächlich durch die Neurodegeneration bedingt sind, noch aus. So erscheint es essentiell, neben den zahlreichen etablierten antiinflammatorischen Therapien neuroprotektive Ansätze zur Prophylaxe von bleibenden Behinderungen zu suchen.

\subsubsection{EPIDEMIOLOGIE}

Bei der Mehrzahl der Patienten manifestiert sich die MS im Alter zwischen 20 und 40 Jahren. Besonders an der schubförmigen Verlaufsform erkranken Frauen doppelt so häufig wie Männer. Während bis in die achtziger Jahre die damalige Diagnostik nach den SchuhmacherKriterien einen Krankheitsbeginn im Alter zwischen 10 und 50 Jahren forderte (Schumacher 1974), wird heutzutage eine Manifestation der Erkrankung vor dem 10. Lebensjahr nicht ausgeschlossen (Ruggieri et al. 1999). Zusätzlich ist bekannt, dass das Auftreten der MS sogar jenseits der 8. Lebensdekade möglich ist (Noseworthy et al. 1983).

Die Erkrankung betrifft weltweit schätzungsweise eine Millionen Menschen und ist damit die häufigste neurologische Erkrankung des jungen Erwachsenenalters, die nicht traumatischer Genese ist (Flachenecker et al. 2005). Regionen mit hohem Erkrankungsrisiko und 
Prävalenzraten über 30 pro 100000 Einwohner sind Europa, Nordamerika und Australien (Kurtzke 1985). Etwa $8 \%$ der in unseren Breitengraden in neurologischen Kliniken behandelten Patienten leiden an MS (Poeck und Hacke 1998). Betrachtet man die weltweite Verteilung, wird sichtbar, dass die Prävalenzraten einem Gradienten folgen, wobei die Erkrankung in Äquatornähe selten ist und in Richtung der Pole stetig zunimmt (Kurtzke 1980).

Aus Migrationsstudien wird ersichtlich, dass die Umsiedelung aus einer Hochrisikoregion wie Europa in eine Region mit niedrigem Erkrankungsrisiko zu einer Aneignung des Risikos der neuen Umgebung führt, und umgekehrt (Gale and Martyn 1995). Allerdings wird dieses Phänomen nur beobachtet, wenn die Migration vor dem 15. Lebensjahr stattfindet.

\subsection{3 ÄTIOLOGIE}

Die genaue Ätiologie der MS ist bislang ungeklärt, jedoch kann sie aufgrund der bisherigen Erkenntnis über ihre Pathogenese einer Gruppe von chronisch entzündlichen Erkrankungen zugeordnet werden, deren gemeinsamer Nenner pathogene Mechanismen sind, die durch ein Zusammenspiel von genetischen Faktoren, Umwelteinflüssen und zellulären Immunreaktionen zustande kommen. Über die Jahre wurden unterschiedlichste Hypothesen aufgestellt, die jedoch alle nicht endgültig beweisend waren.

Die MS ist eine polygenetische Erkrankung, wobei die einzelnen beeinflussenden Gene noch nicht genau bekannt sind (Sawcer et al. 2002). Es ist inzwischen allgemein anerkannt, dass genetische Faktoren, welche die Reaktionsweise des Immunsystems kontrollieren, mit der Pathogenese in Zusammenhang gebracht werden können. Besonders intensiv erforscht ist die Beziehung der MS zum humanen Leukozytenantigen (HLA; Haines et al. 1996). Die Empfänglichkeit für MS ist signifikant assoziiert mit dem Tragen des HLA-DR2-Allels (Madsen et al. 1999).

In Zwillingsstudien wurde bei monozygoten Zwillingen eine Konkordanzrate von $30 \%$ bezüglich der Krankheit gefunden, während zwischen zweieiigen Zwillingen lediglich in $3 \%$ und bei Geschwistern in $2 \%$ eine Übereinstimmung der Erkrankung zu finden ist (Ebers et al. 1986; Oksenberg und Barcellos 2000). Es wird somit erkenntlich, dass der MS zwar in einigen wenigen Fällen eine genetische Komponente zugeschrieben werden, sie jedoch nicht als reine genetische Erkrankung gelten kann.

Andere Studien weisen auf eine infektiöse Ätiologie der MS hin und suggerieren, dass eine frühe Infektionen durch das Humane Herpesvirus 6 (Soldan et al. 1997), das Masernvirus 
(Burgoon et al. 1999) oder das Epstein-Barr-Virus (Ascherio et al. 2001; Aloisi et al. 2008) eine erhöhte Erkrankungswahrscheinlichkeit mit sich zieht. 


\subsubsection{PATHOLOGIE UND PATHOPHYSIOLOGIE}

Bei der MS handelt es sich um einen chronisch entzündlichen Entmarkungsprozess im ZNS. Dieser Entmarkungsprozess weist Prädilektionsstellen für die Sehnerven, den Hirnstamm, das Rückenmark, das Kleinhirn und die periventrikuläre weiße Substanz auf. Das wichtigste morphologische Charakteristikum stellt der Nachweis von multifokalen, entmarkten und scharf begrenzten Plaques dar. Diese Plaques entstehen auf dem Hintergrund einer entzündlichen Reaktion, die vorwiegend aus T-Lymphozyten und Makrophagen besteht. Daneben können in geringen Mengen auch B-Lymphozyten und Plasmazellen gefunden werden. Zudem ist die Entzündungsreaktion mit einer Hochregulation unterschiedlichster Zytokine wie beispielsweise des Interleukins-2 (IL-2) und des Tumornekrosefaktors- $\alpha$ (TNF- $\alpha$ ) assoziiert (Cannella und Raine 1995).

Obwohl Läsionen unterschiedlicher Patienten ein ähnliches Entzündungsmuster aufweisen, ist es in den letzten Jahren gelungen, eine in vier Gruppen eingeteilte Klassifikation aufzustellen, die die verschiedenen Muster der Myelindestruktion definiert (Ascherio et al. 2001; Lassmann et al. 2001; Brück und Stadelmann 2005). In Typ-I- und Typ-II-Läsionen sind hauptsächlich aktivierte Makrophagen und T-Lymphozyten an dem Entmarkungprozess beteiligt, wobei in Typ-II-Läsionen zusätzlich Immunglobuline und aktivierte Komplementkomponenten gefunden werden können. Die Remyelinisierung ist in diesen beiden Läsionen ausgeprägt. Typ-III- und Typ-IV-Läsionen weisen zwar ein sehr ähnliches entzündliches Infiltrat wie Typ I auf, sind jedoch durch eine ausgeprägte Oligodendrogliopathie und Oligodendrozytenapoptose von den restlichen zwei Typen zu unterscheiden. Die verringerte Zellzahl der Oligodendrozyten in Typ-IV-Läsionen befindet sich hauptsächlich in der der Plaque benachbarten weißen Substanz und führt dort dann zu einer sekundären Entmarkung. Diese Einteilung in vier histologisch verschiedene Typen stellt einen Versuch dar, eine gewisse Ordnung in das heterogene Krankheitsbild der MS zu bringen, um eine speziell für jeden der Subtypen perfektionierte Therapie etablieren zu können. Die vielseitige Ausprägung der MS, die sowohl auf histologischer, als auch auf makroskopischer und klinischer Ebene zu finden ist, zieht nämlich nicht nur eine gewisse Komplexität im Verständnis der Erkrankung mit sich, sondern erschwert auch die Suche nach idealen, individuell angepassten Therapiekonzepten.

MS-Läsionen können entsprechend ihrer Entmarkungsaktivität in aktive und inaktive Plaques unterteilt werden. Dabei sind der Aktivierungszustand der Makrophagen und die Phagozytose von Myelinabbauprodukten verlässliche Indikatoren eines aktiven Entmarkungsprozesses (Brück et al. 1995). Chronisch inaktive Läsionen lassen eine ausgeprägte fibrilläre Gliose, 
eine geringe Zellzahl einschließlich der myelinbildenden Oligodendrozyten und keinen aktiven Myelinabbau erkennen.

Auch die Axone in MS-Läsionen bleiben vom degenerativen Prozess nicht verschont (Charcot 1868; Kornek und Lassmann 2003). Vor allem in akuten Herden findet man eine deutlich verringerte Axondichte, die schon im Frühstadium der Krankheitsentwicklung nachweisbar ist (Ferguson et al. 1997) und auf einem niedrigeren Niveau während der folgenden Jahre persistiert (Kuhlmann et al. 2002). Zusätzlich zu der Axondegeneration treten auch direkte Schäden an Neuronen auf (Peterson et al. 2001). Forschungsergebnisse in den letzten Jahren zeigten, dass die Schädigung von Axonen eine der wichtigsten morphologischen Ursachen für eine permanente klinische Behinderung ist (Stoll und Müller 1999; Bjartmar und Trapp 2001). Magnetresonanztomographische (MRT-) Studien konnten diese Hypothese bestätigen. In der $\mathrm{T}_{1}$-gewichteten Sequenz, welche wegen des stärkeren Signals eine bessere Gewebeauflösung, aber einen geringeren Gewebekontrast als $\mathrm{T}_{2}$-gewichtete Sequenzen aufweist, korrelierte sowohl das Volumen der hypointensen Läsionen (,black holes“), als auch das Ausmaß der Hirnatrophie, beides allgemein akzeptierte Marker für axonale Schädigung, mit dem Behinderungsgrad (Grimaud et al. 1999; Fisher et al. 2000; Paolillo et al. 2000). Wesentlich genauer kann die axonale Schädigung mittels Azetylaspartat-Messung während einer magnetresonanzspektroskopischen (MRS-) Untersuchung quantifiziert werden. Azetylaspartat ist ein Metabolit, welcher nur in neuronalen Strukturen des ZNS zu finden ist. Auch diese Untersuchung deutet auf eine Korrelation von Axondegeneration und klinischer Einschränkung bei MS-Patienten hin (Matthews et al. 1998; De Stefano et al. 2007).

Neuere neuropathologische Studien zeigen auch, dass diese Läsionen nicht nur einen Entmarkungsprozess, sondern auch Zeichen der Remyelinisierung aufweisen. In chronischen Herden ist die Wiederherstellung der Myelinscheiden oft inkomplett, während sie in akuten und frühen Plaques meist den gesamten Läsionsbereich erfasst (Brück et al. 2003). Durch die inkomplette Remyeliniserung in chronischen Läsionen kann die fehlende Remission von Schüben nach einer längeren Krankheitsdauer sehr gut erklärt werden. Per definitionem wird ein zuvor lädiertes Areal mit vollständiger Remyelinisierung Markschattenherd genannt. Diese Markschattenherde sind gegenüber der gesunden weißen Substanz scharf abgrenzbar und weisen im Vergleich zu gesunden Markscheiden eine geringere Anfärbbarkeit des Myelins auf. 


\subsubsection{KLINIK}

Die Symptome der MS können sehr unterschiedlich sein. Es treten spastische Paresen, Gangund Extremitätenataxien, Koordinationsstörungen, sowie Parästhesien und Blasen- oder Sexualdysfunktionen auf. Zusätzlich sind Müdigkeit sowie Gedächtnis- und Aufmerksamkeitsstörungen typisch. Die häufigste pathologische Auffälligkeit in der MS-Diagnostik spiegeln Pyramidenbahnläsionen wider, welche sich in der klinischen Untersuchung unter anderem anhand von gesteigerten Muskeleigenreflexen und einer spastischen Tonuserhöhung der Muskulatur darstellen.

Die Optikusneuritis hat für die Frühdiagnostik eine besondere Bedeutung. Rund $30 \%$ der Patienten mit einer bestätigten MS weisen eine Optikusneuritis bei Erstmanifestation der Erkrankung auf (Wikstrom et al. 1980). Die Entzündung des Nervus opticus äußert sich bei Patienten mit dem Gefühl des Verschwommen- oder Verschleiert-Sehens und/oder einer Visusminderung unterschiedlichen Ausmaßes. Häufig sind währenddessen auch gewöhnliche Augenbewegungen von supraorbitalen oder orbitalen Schmerzen begleitet. Diese bilden sich meist spontan und vor Erholung des Visus zurück. Nach einer akuten Optikusneuritis kann in etwa $90 \%$ der Fälle mit einer guten Erholung des Visus gerechnet werden (Barnes und McDonald 1992).

Der Krankheitsverlauf der MS ist heterogen. Es gibt drei unterschiedliche Verlaufsformen (Lublin und Reingold 1996). Der klinische Verlauf der MS kann schubförmig, primär chronisch progredient oder sekundär chronisch progredient erscheinen. Der schubförmige Verlauf ist definiert durch klare Schübe mit vollständiger Remission oder verbleibenden Residuen, wobei in Intervallen zwischen den Schüben keine Krankheitsprogression zu verzeichnen ist. Von einem primär chronisch progredienten Verlauf spricht man, wenn eine konstante Verschlechterung von Krankheitsbeginn an besteht. Gelegentliche Plateaus und geringfügige Verbesserungen sind dabei möglich. Die sekundär chronisch progrediente MS ist durch einen initial schubförmigen Verlauf charakterisiert, dem eine Phase der progressiven Verschlechterung mit gelegentlichen Schüben, geringfügigen Remissionen oder Plateaus folgen kann.

\subsubsection{THERAPIE}

Aufgrund der klinisch unterschiedlichen Manifestation der Krankheit und der recht großen Anzahl an möglichen Symptomen muss das Therapiekonzept auf jeden Patienten individuell abgestimmt werden. Prinzipiell gibt es drei verschiedene therapeutische Ansätze: die den Verlauf beeinflussende Langzeittherapie, die Schubtherapie und die symptomatische Therapie. Meist gilt es, eine Kombination dieser drei Therapieansätze zu finden. 
Bitsch und Brück (2002) befürworten aufgrund ihrer neuropathologischen Studien eine Therapie, welche auf die histopathologischen Muster der Erkrankung abgestimmt ist. Es gibt Hinweise, dass Fälle des Typ-II-Musters auf Plasmapherese gut ansprechen, während Fälle der Muster I und III nach Behandlung mit Plasmapherese keine Besserung zeigen (Keegan et al. 2005).

Zur Therapie eines akuten Schubes werden Glukokortikoide gegeben (Goodin et al. 2002). Diese wirken gleichzeitig anti-inflammatorisch und anti-ödematös. Belegt ist, dass Glukokortikoide einen Besserungszustand nach MS-Schüben beschleunigen, jedoch findet sich langfristig keine Verringerung der funktionellen Defizite (Andersson und Goodkin 1996). Wahrscheinlich hemmen Glukokortikoide auch die durch den Tumornekrosefaktor- $\alpha$ (TNF- $\alpha$ ) und das Interferon- $\gamma$ (INF- $\gamma$ ) vermittelte Apoptose der Oligodendrozyten (Melcangi et al. 2000). Allerdings wurde auch gezeigt, dass sie im Tiermodell den neuronalen Zelltod fördern können (Diem et al. 2003).

Zur Langzeittherapie und Schubprophylaxe können immunmodulatorische und immunsupprimierende Substanzen eingesetzt werden. So finden als erste Wahl $\beta$-Interferon (Bayas und Gold 2003; Rieckmann 2006; Kleinschnitz et al. 2007) oder Glatiramerazetat Verwendung (Rieckmann 2009). Bei aktivem Krankheitsverlauf kann eine Therapieeskalation mittels Natalizumab oder Mitoxantron vorgenommen werden (Putzki et al. 2009; Rieckmann 2009).

So zahlreich die anti-inflammatorischen Therapieoptionen sind, findet sich momentan jedoch noch keine Möglichkeit, das Fortschreiten der Krankheit zu stoppen. Gerade eine Kombination aus einer neuroprotektiven und einer anti-inflammatorischen Therapiestrategie erlaubt Hoffnung, da somit nicht nur mikroskopisch sichtbar entzündliche Veränderungen eingedämmt werden können, sondern auch eine klinische Verbesserung erreicht werden kann. So zeigen aktuelle Studien bei MS-Patienten mit chronisch progredientem Krankheitsverlauf, dass die aktive Entzündungsreaktion durch die Applikation von Alemtuzumab, einem monoklonalem Antikörper, unterdrückt werden kann, während ein Behinderungsprogress dabei nicht aufzuhalten ist (Coles et al. 2006). Das Fortschreiten der funktionellen Defizite kann mit großer Wahrscheinlichkeit auf die ungehinderte Neurodegeneration zurückgeführt werden und verdeutlicht somit die Notwendigkeit einer ergänzenden neuroprotektiven Behandlungsmöglichkeit für MS-Patienten. 


\subsection{TIERMODELLE DER MULTIPLEN SKLEROSE}

\subsubsection{EXPERIMENTELLE AUTOIMMUNE ENZEPHALOMYELITIS (EAE)}

Die pathogenetisch orientierte Forschung bei neurologischen Erkrankungen des Menschen ist aufgrund der schlechten Zugänglichkeit des ZNS auf experimentelle Modelle angewiesen. Gerade für Krankheiten wie die MS, deren Pathomechanismus noch nicht komplett verstanden wird, ist es von Bedeutung, die klinischen, pathologischen und immunologischen Veränderungen anhand krankheitsspezifischer Modelle möglichst wahrheitsgetreu wieder zu geben, um Rückschlüsse auf die Pathogenese der Erkrankung ziehen zu können. Das Modell der Experimentellen Autoimmunen Enzephalomyelitis (EAE) findet in der derzeitigen MS-Forschung häufigen Gebrauch.

Einen großen Betrag zur Entwicklung der EAE leisteten die beiden Forscher Rivers und Schwentker, die im Jahre 1935 zeigten, dass die Immunisierung von genetisch suszeptiblen Affen mit Hirngewebe zur Entwicklung einer Enzephalomyelitis führt. Daraufhin wurden die Hirnhomogenate durch mehrere Forschungsgruppen auf potentiell enzephalitogene Einzelbestandteile untersucht. Die Ergebnisse zeigten zum großen Teil eine Beteiligung der Myelinproteine. Das am längsten bekannte Protein dieser Gruppe ist das basische Myelinprotein MBP (Kies et al. 1965; Ben-Nun et al. 1981). Eine Immunisierung mit MBP führt zur Ausprägung einer akuten allergischen Enzephalomyelitis, eine entzündliche Erkrankung des ZNS ohne nennenswerte Entmarkung. Weitere Autoantigene, die eine hauptsächlich inflammatorische EAE induzieren, sind unter anderem das Proteolipid-Protein PLP (Cambi et al. 1983; Sobel et al. 1986), das Myelin-assoziierte Glykoprotein MAG (Weerth et al. 1999) sowie das Myelin-assoziierte Oligodendrozyten-Basisprotein MOBP (Kaye et al. 2000).

\subsubsection{MOG-INDUZIERTE EAE}

Eines der wichtigsten Zielantigene in der Pathogenese der entmarkenden Enzephalomyelitis ist das Myelin-Oligodendrozyten-Glykoprotein (MOG; Linington et al. 1993). Dieses aus 218 Aminosäuren bestehende Glykoprotein ist auf myelinbildenden Zellen des ZNS membranständig und somit nicht nur für aktivierte T-Zellen, sondern auch für entmarkende Antikörper erkennbar. Diese Kombination aus autoimmuner T-Zell-Reaktion und humoraler Immunantwort spiegelt das histopathogenetische Erkrankungsbild von MS-Patienten sehr gut wider (Linington et al. 1993; Storch et al. 1998a). Die MOG-EAE bei Ratten führt in etwa $90 \%$ der Fälle zu einer Optikusneuritis, die auch beim Menschen ein typisches Symptom der 
Erstmanifestion einer MS ist (Storch et al. 1998b). Mehrere Studien der letzten Jahre zeigten außerdem, dass die histopathologische und symptomatische Heterogenität der MS-Patienten durch die MOG-induzierte EAE reproduziert werden kann (Storch et al. 1998b; Storch et al. 2006). Anhand von unterschiedlichen Agenzien, die dem Immunogen hinzugeführt werden, oder durch den Gebrauch unterschiedlicher Rattenstämme (Sättler et al. 2008a) kann die Klinik der Tiere nämlich in gewissem Maße modifiziert werden.

Zusätzlich ähnelt die axonale Degeneration im MOG-induzierten EAE-Modell weitgehend dem Degenerationsprozess, den die humane Erkrankung mit sich zieht (Kornek et al. 2000). Durch die Möglichkeit der stereotaktischen Applikation eines fluoreszierenden Farbstoffes in den Colliculus superior können die retinalen Ganglienzellen (RGZ) selektiv angefärbt werden. Des Weiteren ist bekannt, dass bei der EAE der Entzündungsprozess am Sehnerven von einer frühen Degeneration der RGZ begleitet ist (Meyer et al. 2001). Dabei korreliert die reduzierte neuronale Zelldichte mit den Funktionsdefiziten der Tiere, die unter anderem anhand von visuell evozierten kortikalen Potentialen untersucht werden können. Durch die Möglichkeit einer farblichen Markierung der RGZ und auf Basis der zuvor beschriebenen Ergebnisse von Meyer et al. lassen sich somit nicht nur anti-inflammatorische, sondern auch neuroprotektive Therapieansätze erproben.

Aktuelle Therapiestudien, welche unter Zuhilfenahme des MOG-induzierten EAE-Modells durchgeführt wurden, veranschaulichen darüber hinaus die zunehmend wichtiger erscheinende Rolle einer potentiellen Monotherapie, die die Reduktion von sowohl Entzündung als auch neuronalem Zelltod ermöglicht. Zwei der aktuellen Standardmedikamente der MS-Therapie, Methylprednisolon (Diem et al. 2003) und Interferon- $\beta$-1a (Sättler et al. 2006), erwiesen sich dabei als sehr wirksam gegen die entzündliche Infiltration, Demyelinisierung und gegen den axonalen Schaden. Jedoch wurde keine wesentliche Protektion der RGZ und somit kein funktionell relevanter Effekt festgestellt. Gegenteilig dazu verhielt es sich mit dem Glykoprotein-Hormon Erythropoietin (Epo; Sättler et al. 2004), dem ziliaren Nervenwachstumsfaktor (CTNF; Maier et al. 2004) und dem oral verfügbaren Analgetikum Flupirtin (Sättler et al. 2008b). Diese Substanzen schienen zwar neuroprotektiv wirksam zu sein, hatten dabei allerdings keinen maßgeblichen Einfluss auf den entzündlichen Prozess. Demnach wurden Kombinationen aus einer neuroprotektiv wirksamen und einer anti-inflammatorischen Substanz untersucht. Dazu wurde den EAE-Tieren dieser Versuchsreihe Methylprednisolon unter gleichzeitiger Applikation von Epo verabreicht (Diem et al. 2005). In einer weiteren Studie wurde die Kombinationsbehandlung von Flupirtin und Interferon- $\beta$-1a getestet (Sättler et al. 2008b). Die 
gleichzeitige Behandlung von zwei Substanzen erwies sich im Tiermodell prinzipiell als erfolgreich. Inzwischen wird zur weiteren Untersuchung der Kombinationsbehandlung aus Methylprednisolon und Epo eine klinische multizentrische Phase-II-Studie durchgeführt (VisionProtect-Studie; PD Dr. med. Ricarda Diem; Universitätsklinikum Homburg/Saar). Idealerweise sollte zur Reduktion von Entzündung und neuronalem Zelltod eine Monotherapie gefunden werden, sodass das Nebenwirkungsprofil möglichst gering gehalten werden kann und potentielle Medikamenteninteraktionen vermieden werden können.

\subsection{LENKMOLEKÜLE (,GUIDANCE MOLECULES“)}

\subsubsection{AXONREGENERATIONS-HEMMENDE LENKMOLEKÜLE}

ZNS-Läsionen jeglicher Art, auch entzündliche Plaques bei MS-Patienten, sind durch eine gliale Reaktion, inflammatorische Prozesse und Wundheilungsvorgänge charakterisiert, wobei die gliale Reaktion einen wesentlichen Beitrag zur Ausbildung von permanenten klinischen Behinderungen liefert (Brück und Stadelmann 2003). In den geschädigten Arealen findet sich ein Bild von komplexer zellulärer und molekularer Interaktion mit dem Ziel der Regeneration des initial zerstörten Gewebes (Fitch et al. 1999). Dabei scheint die gliale Antwort auf ZNS-Verletzungen unterschiedlichster Pathologien weitgehend ähnliche histopathologische Eigenschaften zu zeigen (Fawcett und Asher 1999).

Das Endprodukt dieses Vorganges ist die gliale Narbe. Interessanterweise zeigen geschädigte Axone innerhalb dieser Läsionen keine oder eine nur sehr geringe Eigenaktivität zur Wiederherstellung ihrer Struktur (Silver und Miller 2004). Dieses Phänomen scheint auf den ersten Blick verwunderlich, denn, während früher angenommen wurde, dass die Nervenfasern im adulten ZNS ihre Fähigkeit zur Regeneration verloren haben (Le Gros Clark 1943), ist seit

geraumer Zeit bekannt, dass Axone unter experimentellen Bedingungen sogar innerhalb von Läsionsarealen langsam wieder aussprossen können (Liu und Chambers 1958; Guth et al. 1985). Zusätzlich konnte kürzlich ein Regenerieren von überlebenden Axonen über kurze Distanzen in außerhalb der Läsion gelegene Bereiche nachgewiesen werden (Freund et al. 2006; Taylor et al. 2006). In vivo allerdings scheint die axonale Regeneration weitaus komplexeren Mechanismen zu unterliegen. Mikroskopische Untersuchungen gaben Einblick in eine sehr rasch fortschreitende Dystrophie der Wachstumskegel lädierter Axone (Li und Raisman 1995; Misgeld und Kerschensteiner 2006). Der Wachstumskegel beschreibt die bewegliche, durch Aktinfilamente stabilisierte Erweiterung eines sich entwickelnden Axons, die auf extern präsentierte Lenkmoleküle (,guidance molecules“) in Form eines 
Wachstumsvorganges in eine definierte Richtung reagieren kann. Der dystrophe Wachstumskegel ist jedoch im Verglich zu seinem intakten Korrelat keineswegs als regungslose Struktur zu betrachten. So wird er im Falle einer axonalen Verletzung nur in einen Ruhezustand versetzt (Tom et al. 2004) und kann daher nicht alleinig für die fehlende oder stark eingeschränkte Axonregeneration verantwortlich gemacht werden. Mittlerweile ist bekannt, dass in passender Umgebung nicht nur korpuskuläre Anteile diesen hemmenden Effekt auf regenerierende Axone ausüben. Vielmehr scheint dafür ein komplexes Zusammenspiel von lädierter Umgebung, aktivierten, sekretorischen Zellen und bestimmten Lenkmolekülen verantwortlich zu sein. Wie in diesem Paragraph beschrieben, existieren also einige Lenkmoleküle mit zweierlei Funktion. Einerseits agieren sie für das wachsende Axon richtungsbestimmend, andererseits können sie in einem passenden Milieu die axonale Regeneration hemmen.

In diesem Zusammenhang wird unter anderem das Lenkmolekül Nogo-A diskutiert (Prinjha et al. 2000; Chen et al. 2000; GrandPré et al. 2000). Mehrere Studien der letzten Jahre konnten durch die Behandlung mit einem neutralisierenden Antikörper gegen Nogo-A eine Verbesserung und Verzögerung der lokomotorischen Behinderung aufgrund einer erhöhten Rate an Axonregeneration in Rattenmodellen mit Rückenmarksläsionen verzeichnen (Bregman et al. 1995; Merkler et al. 2001). Kürzlich wurde von Karnezis et al. (2004) sogar die Antikörperbehandlung gegen Nogo-A im entzündlich degenerativen EAE-Modell untersucht. Es konnte dabei eine neuroprotektive Wirkung, welche sich in einer Verminderung der klinischen Behinderungen äußerte und histologisch durch eine niedrigere Rate an lädierten Axonen nachweisbar war, beobachtet werden.

\subsubsection{REPULSIVE GUIDANCE MOLECULE}

Eine weiteres Lenkmolekül mit ähnlicher repulsiver Wirkung auf die Axonregeneration ist das Repulsive Guidance Molecule (RGM; Stahl et al. 1990; Müller et al. 1990; Matsunaga et al. 2006). Ursprünglich wurde das Protein RGM auf der Suche nach Lenkmolekülen, die die retinotektale Projektion von RGZ beeinflussen, gefunden. Es zeigte sich durch in-vitro-Analysen, dass RGM die Destruktion von temporalen, aber nicht von nasalen Wachstumskegeln der RGZ induziert und damit eine axonspezifische, repulsive Aktivität an den Tag legt (Monnier et al. 2002). Zuvor konnte dies schon für die Lenkmoleküle Ephrin A2 und Ephrin A5 im retinalen Projektionssystem gezeigt werden (Drescher 1997; Wahl et al. 2000). 
RGM ist ein $33 \mathrm{kDa}$ großes, membrangebundenes Glykoprotein, das keine Sequenzhomologie zu anderen Lenkmolekülen aufweist (Matsunaga et al. 2004). Seine Struktur besteht aus einem Signalpeptid am N-terminalen Ende und einem C-terminalen Glykosylphosphatidylinositol-Anker. Des Weiteren weist das Molekül ein Strukturelement des von-Willebrand-Faktors Typ D sowie einer bestimmten Aminosäuresequenz auf, der RGD-Struktur (Arginin - Glycin - Asparaginsäure), welche in Zell-Zell-Interaktionen mit noch weitgehend unbestimmter Funktion involviert ist (Monnier et al. 2002). Zusätzlich wurde eine hochkonservierte Sequenz gefunden, die allen Mäuse-RGMs und dem HühnerHomolog gemeinsam ist (siehe Abbildung 1.1). Bis vor kurzem wurde vermutet, dass nur das C-terminale Ende den repulsiven und lenkenden Effekt des Moleküls ausmacht (Rajagopalan et al. 2004). Allerdings konnte eine neue Studie zeigen, dass dieses Endstück konstant durch Disulfidbrücken mit dem N-terminalen Ende verbunden ist und somit auch beide an der retinalen Axonführung während der Entwicklung beteiligt sein könnten (Tassew et al. 2009).

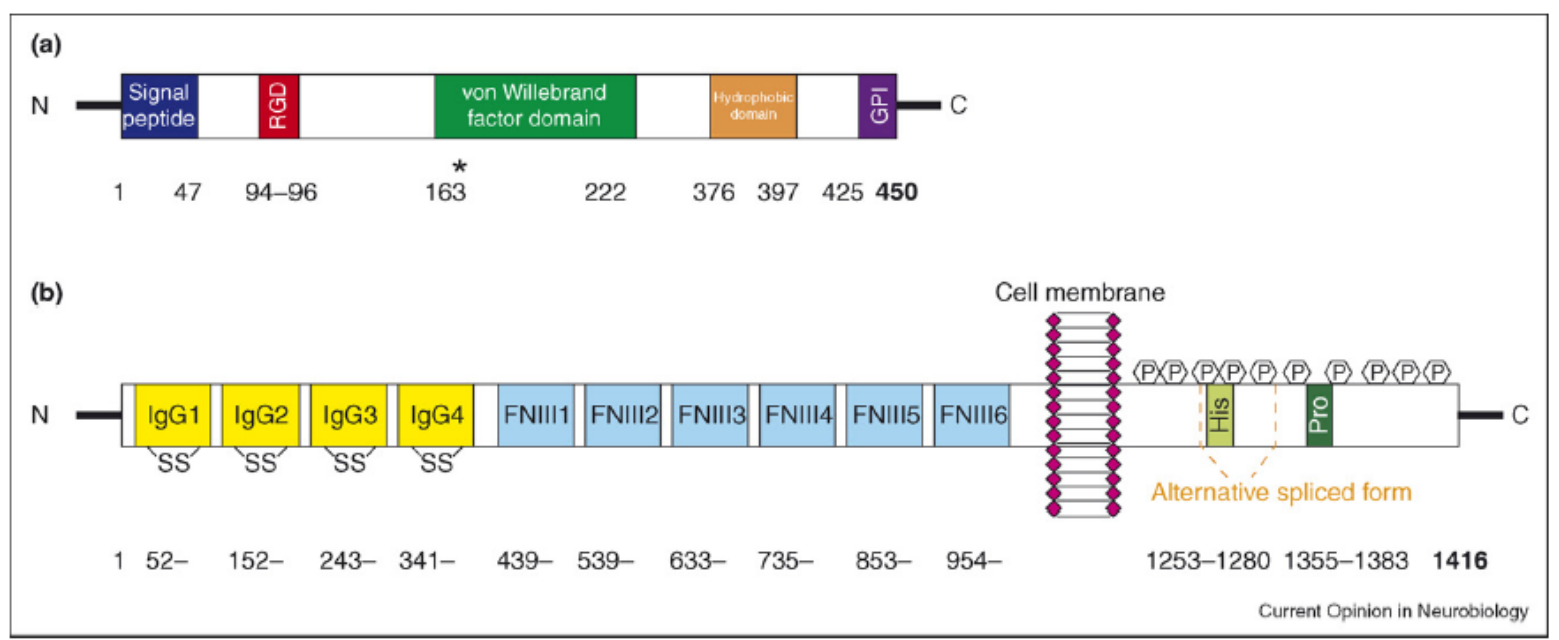

Structure of RGMa and neogenin. The different domains of (a) human RGMa and (b) its receptor neogenin are shown. RGMa contains a potential cleavage site at $\mathrm{N}$-terminal amino acid 168 (indicated by the asterisk). Potential phosphorylation sites are marked (hexagonal boxes).

Abbildung 1.1 Die Graphik zeigt den molekularen Aufbau von RGMa und deren Rezeptor Neogenin; entnommen aus Yamashita et al. 2007, S. 30

Im Genom der Maus wurden drei homologe Moleküle (RGMa, RGMb, RGMc) des HühnerRGM (cRGM) gefunden (Schmidtmer und Engelkamp 2004), die ein unterschiedliches Verteilungsmuster im ZNS und in der Peripherie aufweisen. RGMa und RGMb werden während der neuronalen Entwicklung des ZNS konstant exprimiert, jedoch sehr distinkt und nicht zeitgleich (Niederkofler et al. 2004). RGMc wird ausschließlich in quergestreifter Muskulatur und Myokard gefunden. Auf der Basis von Expressionsanalysen scheinen sich die 
Subtypen RGMa und RGMb also funktionell von RGMc sehr zu unterscheiden (Oldekamp et al. 2004; Schmidtmer und Engelkamp 2004).

Der Wirkmechanismus von RGMa wird über eine Bindung an den Neogenin-Rezeptor (Rajagopalan et al. 2004) und über die Aktivierung der RhoA-Rhokinase-Kaskade vermittelt (Hata et al. 2006). Der Neogenin-Rezeptor wurde ursprünglich aus dem Cerebellum embryonaler Hühner als Homolog des Netrin-Rezeptors isoliert (Yamashita et al. 2007). Auch das Protein Netrin kann an den Neogenin-Rezeptor binden, allerdings ist die Bindungsaffinität von RGMa $\left(\mathrm{K}_{\mathrm{d}}=230 \mathrm{pM}\right)$ zu Neogenin um einiges höher als von Netrin $\left(\mathrm{K}_{\mathrm{d}}=2 \mathrm{nM}\right)$. Neogenin besitzt vier hochkonservierte IgG-Domänen, gefolgt von sechs Fibronektin-Einheiten sowie einer transmembranösen und einer intrazellulären Struktur, wobei die Interaktion mit RGMa vermutlich über die Fibronektin-Einheiten erfolgt (Matsunaga et al. 2004). Aktuelle Untersuchungen von Matsunaga et al. zeigen, dass eine Überexpression von Neogenin apoptotischen Zelltod induziert. Wird jedoch zusätzlich RGMa überexprimiert, kann diese pro-apoptotische Wirkung aufgehoben werden (Matsunaga und Chédotal 2004). Folglich scheint der Rezeptor eine Autoapoptose zu induzieren, falls kein Ligand bindet (De Vries und Cooper 2008).

Unter den beiden ZNS-spezifischen RGM-Subtypen (RGMa und RGMb) wird RGMa in Studien bevorzugt untersucht, da es bis zum heutigen Zeitpunkt das intensiver studierte Molekül ist. Expressionsanalysen von RGMa im menschlichen Gewebe deuten auf ein vermehrtes Vorkommen in den Perikaryen einiger Neurone, in Zellen der glatten Muskulatur, Endothelzellen und in Zellen des Plexus choroideus hin. Außerdem ist RGMa auf den Membranen der Oligodendrozyten exprimiert, was vermuten lässt, dass das Molekül eine Kommunikationsrolle zwischen Axon und Myelin innehat. An post-mortem-Studien an menschlichen Gehirnen von Patienten nach fokaler zerebraler Ischämie (focal cerebral ischemia; FCI) und traumatischer Gehirnverletzung (traumatic brain injury; TBI) zeigt sich eine Akkumulation von RGMa in den lädierten Arealen (Schwab et al. 2005a). Eine Antagonisierung von RGMa mittels eines neutralisierenden Antikörpers zeigt in diesem Modell ein vermehrtes Aussprossen von zuvor lädierten Axonen (Hata et al. 2006; Kyoto et al. 2007). Ein axonregenerativer Charakter durch Antikörperbehandlung bewies sich demnach prinzipiell als erfolgreich. Ob sich eine derartige Antikörpertherapie im EAE-Modell als neuroprotektiv und/oder anti-inflammatorisch darstellt, ist bisher noch nicht untersucht worden. Wie in den zuvor exemplarisch dargelegten Studien beschrieben, lag der Fokus der bisherigen Forschungsarbeiten auf der axonregenerativen Komponente des Moleküls. Da ein axonerhaltender und entzündungshemmender Einfluss bereits für die Neutralisierung von 
Nogo-A, einem Molekül der gleichen Familie (siehe Abschnitt 1.3.1) nachgewiesen werden konnte, erscheint es vielversprechend, durch die Applikation eines Antikörpers gegen RGMa ähnliche Erfolge zu erzielen und womöglich damit einen innovativen Ansatzpunkt für eine neuroprotektive MS-Therapie zu finden.

\subsection{ZIELSETZUNG DER ARBEIT}

Multiple Sklerose beschreibt eine autoimmun entzündliche Erkrankung des ZNS, deren Ätiologie und Pathogenese bislang noch nicht vollständig verstanden wird. MS-Therapien der heutigen Medizin sind auf ihren anti-inflammatorischen Effekt beschränkt. Insbesondere in fortgeschrittenen Krankheitsstadien können diese Behandlungskonzepte die durch die sich akkumulierende Neurodegeneration hervorgerufenen Behinderungen nicht aufhalten. Daher stellen Therapieansätze mit einer sowohl anti-inflammatorischen als auch neuroprotektiven Wirkung eine vielversprechende Ergänzung zu den aktuellen Behandlungsstrategien dar.

Das Ziel dieser Arbeit ist es, erstmalig den therapeutischen Einsatz eines Antikörpers gegen das primär als Inhibitor auf das Axonwachstum agierende RGMa-Molekül im Rattenmodell der MOG-EAE zu evaluieren. Da durch die neutralisierende Funktion eines Antikörpers gegen Nogo-A, ein Myelin-assoziiertes Protein mit ähnlicher axonrepulsiver Wirkung, neuroprotektive Effekte erzielt werden konnten (Karnezis et al. 2004), lautet die Hypothese dieser Arbeit, dass dies auch für die Hemmung des RGMa-Moleküls zutreffen könnte. Hauptaugenmerk sollte dabei auf die Optikusneuritis gelegt werden, da sie bei Erstmanifestation der menschlichen Erkrankung ein sehr häufiges Symptom darstellt (Wikstrom et al. 1980) und im Tiermodell einer histopathologischen, quantifizierenden Untersuchung leicht zugänglich ist.

Folgende Teilaspekte werden bei der Auswertung berücksichtigt:

- Expressionsanalysen von RGMa im Optikusneuritis-Modell

- Wirkung des RGMa-Antikörpers auf die klinischen Funktionsdefizite der Tiere

- Wirkung des RGMa-Antikörpers auf das neuronale Überleben der Tiere

- Wirkung des RGMa-Antikörpers auf den inflammatorischen und axondegenerativen Prozess der Optikusneuritis 


\section{MATERIAL UND METHODEN}

\subsection{MATERIAL}

\subsubsection{CHEMIKALIEN}

Tabelle 2.1 Allgemeine Chemikalien

\begin{tabular}{|l|l|}
\hline \multicolumn{1}{|c|}{ Chemikalien } & \multicolumn{1}{c|}{ Bezugsquelle } \\
\hline Fluorogold & Fluorochrome Inc., Englewood, CO, USA \\
\hline Immersionsöl Immersol $^{\mathrm{TM}}$ 518F & Carl Zeiss, Oberkochen, Deutschland \\
\hline Paraformaldehyd (PFA) & Merck, Darmstadt, Deutschland \\
\hline Salzsäure, rauchend 37 \% & Merck, Darmstadt, Deutschland \\
\hline Sterofundin & B Braun, Melsungen, Deutschland \\
\hline
\end{tabular}

Tabelle 2.2 Chemikalien für die Histopathologie

\begin{tabular}{|c|c|}
\hline Chemikalien & Bezugsquelle \\
\hline Ammoniak $\left(\mathrm{NH}_{3}\right) 32 \%$ & Merck, Darmstadt, Deutschland \\
\hline Einschlussmittel Roti ${ }^{\circledR}$ Histokitt II & Roth, Karlsruhe, Deutschland \\
\hline Essigsäure/Eisessig & Merck, Darmstadt, Deutschland \\
\hline Ethanol (reinst) & Merck, Darmstadt, Deutschland \\
\hline Ethanol (vergällt) & Chemie-Vertrieb, Hannover, Deutschland \\
\hline Formalin/Formaldehydlösung & Merck, Darmstadt, Deutschland \\
\hline Hämalaun & Roth, Karlsruhe, Deutschland \\
\hline HCl-Alkohol & Merck, Darmstadt, Deutschland \\
\hline Horse serum & PAA Laboratories GmbH, Pasching, Österreich \\
\hline Lithiumcarbonat & Sigma-Aldrich, Steinheim, Deutschland \\
\hline Natriumthiosulfat & Sigma-Aldrich, Steinheim, Deutschland \\
\hline Normal goat serum (NGS) & PAA Laboratories GmbH, Pasching, Österreich \\
\hline Paraffin (Paraplast PLUS) & Roth, Karlsruhe, Deutschland \\
\hline Perjodsäurelösung $1 \%$ & Sigma-Aldrich, Steinheim, Deutschland \\
\hline Salpetersäure $65 \%$ & Merck, Darmstadt, Deutschland \\
\hline Salzsäure, rauchend $37 \%$ & Merck, Darmstadt, Deutschland \\
\hline Schiffs Reagenz & Sigma-Aldrich, Steinheim, Deutschland \\
\hline Silbernitrat $\left(\mathrm{AgNO}_{3}\right)$ & Roth, Karlsruhe, Deutschland \\
\hline Solvent Blue 38 (Luxol-Fast-Blue, LFB) & Sigma-Aldrich, Steinheim, Deutschland \\
\hline
\end{tabular}




\begin{tabular}{|l|l|}
\hline Wasserstoffperoxid $\left(\mathrm{H}_{2} \mathrm{O}_{2}\right) 30 \%$ & Merck, Darmstadt, Deutschland \\
\hline Xylol (Isomere) & Roth, Karlsruhe, Deutschland \\
\hline
\end{tabular}

\subsubsection{VERBRAUCHSMATERIALIEN UND GERÄTE}

Tabelle 2.3 Verbrauchsmaterialien

\begin{tabular}{|l|l|}
\hline \multicolumn{1}{|c|}{ Verbrauchsmaterial } & \multicolumn{1}{c|}{ Bezugsquelle } \\
\hline Deckgläser & Menzel-Gläser, Braunschweig, Deutschland \\
\hline Falkon-Reaktionsgefäße $(15 \mathrm{ml} / 50 \mathrm{ml})$ & Becton Dickinson, New York, USA \\
\hline Glaspasteurpipetten $(150 \mathrm{~mm})$ & WU Mainz, Deutschland \\
\hline Kanülen & B Braun, Melsungen, Deutschland \\
\hline Objektträger SUPERFROST PLUS & Menzel-Gläser, Braunschweig, Deutschland \\
\hline Petrischalen & Sarstedt, Nümbrecht, Deutschland \\
\hline Pipettenspitzen & Eppendorf, Wesseling-Berzdorf, Deutschland \\
\hline Reaktionsgefäße $(0,5 / 1,5 / 2 \mathrm{ml})$ & Sarstedt, Nümbrecht, Deutschland \\
\hline Skalpelle & B Braun, Melsungen, Deutschland \\
\hline Spritzen $(1 \mathrm{ml} / 10 \mathrm{ml})$ & Becton Dickinson, Heidelberg, Deutschland \\
\hline
\end{tabular}

Glasware wurden von den Firmen Schütt (Göttingen, Deutschland) oder VWR (Darmstadt, Deutschland) bezogen.

Tabelle 2.4 Geräte

\begin{tabular}{|l|l|}
\hline \multicolumn{1}{|c|}{ Geräte } & \multicolumn{1}{c|}{ Bezugsquelle } \\
\hline Feinwaage BL 210S & Sartorius, Göttingen, Deutschland \\
\hline Grid- Okular 44 41 32(01) & $\begin{array}{l}\text { Carl Zeiss MicroImaging, Göttingen, } \\
\text { Deutschland }\end{array}$ \\
\hline Handdispenser HandyStep electronic & Brand, Wertheim, Deutschland \\
\hline Magnetrührer Combimag RCO & IKA Labortechnik, Staufen, Deutschland \\
\hline
\end{tabular}

\begin{tabular}{|l|l|}
\hline Mikroskop Axioplan 2 & $\begin{array}{l}\text { Carl Zeiss MicroImaging, Göttingen, } \\
\text { Deutschland }\end{array}$ \\
\hline Mikroskop Axiovert 25 & $\begin{array}{l}\text { Carl Zeiss MicroImaging, Göttingen, } \\
\text { Deutschland }\end{array}$ \\
\hline pH Meter PB-20 & Sartorius, Göttingen, Deutschland \\
\hline
\end{tabular}




\begin{tabular}{|l|l|}
\hline $\begin{array}{l}\text { Reinstwasser Anlage SARTOPORE 2, } \\
\text { arium 611 VF }\end{array}$ & Sartorius, Göttingen, Deutschland \\
\hline Ultramikrotom EM UC6 & Leica Microsystems, Wetzlar, Deutschland \\
\hline Vortex Mixer 7-2020 & neoLab, Heidelberg, Deutschland \\
\hline Waage BL 3100 & Sartorius, Göttingen, Deutschland \\
\hline Zentrifugen Centrifuge 5415 C+R & Eppendorf, Wesseling-Berzdorf, Deutschland \\
\hline
\end{tabular}

\subsubsection{KITS UND ANTIKÖRPER}

Tabelle 2.5 Verwendete Kits

\begin{tabular}{|l|l|}
\hline \multicolumn{1}{|c|}{ Kit } & \multicolumn{1}{c|}{ Bezugsquelle } \\
\hline Diaminobenzidin-Kit (DAB) & Vector, Burlingame, CA, USA \\
\hline Vectastain ABC-Kit & Vector, Burlingame, CA, USA \\
\hline
\end{tabular}

Tabelle 2.6 Verwendete Antikörper

\begin{tabular}{|c|c|c|c|c|}
\hline Antikörper & Konjugat & Spezies & Verdünnung & Bezugsquelle \\
\hline$\alpha-\beta-A P P(\operatorname{IgG})$ & - & Maus & 1: 1000 & Milipore, Billerica, MA; USA \\
\hline $\begin{array}{l}\alpha-E D-1(\alpha-\text { Ratte, } \\
\text { CD68) }\end{array}$ & - & Maus & 1: 500 & Serotec, Oxford, UK \\
\hline $\begin{array}{l}\alpha \text {-Maus } \\
\text { (polyklonal) }\end{array}$ & Biotin & Pferd & $1: 200$ & Vector, Burlingame, CA, USA \\
\hline$\alpha$-RGMa (5F9) & - & - & $\begin{array}{l}4 \mathrm{mg} / \mathrm{kg} \mathrm{KG} \\
\text { bzw. } 1 \mathrm{mg} / \mathrm{kg} \\
\mathrm{KG}\end{array}$ & $\begin{array}{l}\text { Abbott GmbH, Ludwigshafen, } \\
\text { Deutschland }\end{array}$ \\
\hline $\begin{array}{l}\alpha \text { - RGMa (8D1, } \\
\alpha \text {-Ratte; } \\
\text { monoklonal) }\end{array}$ & - & - & $\begin{array}{l}4 \mathrm{mg} / \mathrm{kg} \mathrm{KG} \\
\text { bzw. } 1 \mathrm{mg} / \mathrm{kg} \\
\mathrm{KG}\end{array}$ & $\begin{array}{l}\text { Abbott GmbH, Ludwigshafen, } \\
\text { Deutschland }\end{array}$ \\
\hline $\begin{array}{l}\alpha \text {-RGMa } \\
(\alpha-\text { mouse, } \\
\text { polyklonal IgG) }\end{array}$ & - & Ziege & $\begin{array}{l}0,7 \mu \mathrm{g} / \mathrm{ml} \mathrm{bzw.} \\
1 \mu \mathrm{g} / \mathrm{ml} \text { bzw. } 2 \\
\mu \mathrm{g} / \mathrm{ml}\end{array}$ & $\begin{array}{l}\text { R\&D Systems, Mineapolis, } \\
\text { MN, USA }\end{array}$ \\
\hline $\begin{array}{l}\alpha \text {-Ziege } \\
\text { (polyklonal IgG) }\end{array}$ & Biotin & Pferd & $1: 200$ & $\begin{array}{l}\text { Vector Laboratories Inc., } \\
\text { Burlingame, CA, USA }\end{array}$ \\
\hline
\end{tabular}




\subsection{METHODEN}

\section{DURCHFÜHRUNG DER TIEREXPERIMENTELLEN UNTERSUCHUNGEN IM EAE-MODELL}

\subsubsection{VERSUCHSAUFBAU}

Das in dieser Arbeit vorgestellte Projekt zur möglichen neuroprotektiven Wirkung von a-RGMa war initial als Versuchreihe mit 48 Tieren geplant. Die Ratten wurden per Zufallsprinzip in zwei Gruppen eingeteilt: eine Hochdosis- und eine Niedrigdosisgruppe. Die Hochdosisgruppe erhielt 4 mg pro kg Körpergewicht (KG) $\alpha$-RGMa bzw. Placebo. Den 24 Tieren der Niedrigdosisgruppe wurde eine Konzentration von $1 \mathrm{mg}$ pro $\mathrm{kg} \mathrm{KG}$ an $\alpha$-RGMa bzw. an Placebo appliziert. Der Antikörper $\alpha$-RGMa wurde von der Firma Abbot (Ludwigshafen) hergestellt und auf seine Wirksamkeit geprüft. Diese Untersuchungen (unpubliziert) zeigten zusätzlich, dass der Antikörper in den zuvor genannten Konzentrationen bei Ratten in vivo die beste Aktivität aufwies. Neben dem Einsatz des RGMa-Antikörpers wurde mit zwei unterschiedlichen als Placebo wirkenden Substanzen behandelt: 1. PBS und 2. $\alpha$-hRGMa, ein Antikörper, der zwar gegen humanes RGMa gerichtet ist, jedoch keine Bindungstelle für Ratten-RGMa aufweist. Zur vergleichenden Untersuchung des Verums gegen die zwei Kontrollen wurde sowohl die Hochdosis- als auch die Niedrigdosisgruppe per Zufallsprinzip in drei Untergruppen unterteilt. Jede Untergruppe wurde mit einer der drei Testsubstanzen behandelt.

Zur Bestätigung der Ergebnisse wurde das Experiment ein zweites Mal durchgeführt. Diesmal stellten 16 Ratten den Versuchspool dar. Es wurde nur die Niedrigdosis (1 mg pro kg KG) appliziert und als Kontrollsubstanz wurde der hRGMa-Antikörper verwendet.

\subsubsection{VERSUCHSTIERE}

Für alle Versuche wurden weibliche Brown Norway (BN)-Ratten verwendet, die von der Firma Charles River (Sulzfeld, Germany) bezogen wurden. Die Tiere waren im Alter von acht bis zehn Wochen und wurden unter artgerechten und kontrollierten Bedingungen unter Ausschluss von Pathogenen gehalten. Die tierexperimentellen Versuche waren von der zuständigen Behörde in Braunschweig bewilligt worden, relevante Gesetze und Richtlinien wurden befolgt. 


\subsubsection{IMMUNOGEN}

Als Immunogen wurde rekombinantes Ratten-Myelin-Oligodendrozyten-Glykoprotein ${ }^{\text {IgD }}$ (rrMOG) verwendet, welches der N-terminalen Sequenz von Ratten-MOG (aa 1-125) entspricht. Das Protein wurde in Escherichia coli (E. coli) exprimiert und mittels MetallChelat-Chromographie durch den Komplexbildner Sepharose Fast Flow (Pharmacia, Uppsala, Schweden) in $8 \mathrm{M}$ Harnstoff aufgereinigt (Amor et al. 1994). Hierbei wurde ein kontinuierlicher $\mathrm{pH}$-Gradient (von $\mathrm{pH} 6$ auf $\mathrm{pH} 3$ ) eingestellt. Es folgte die Dialyse des zuvor in $6 \mathrm{M}$ Harnstoff gelösten Proteins gegen $0,01 \%$ Natriumacetat. Das gereinigte Protein wurde bei $-80{ }^{\circ} \mathrm{C}$ aufbewahrt.

\subsubsection{INDUKTION DER MOG-EAE}

Die Ratten wurden inhalativ mit Methoxyfluran anästhesiert. Zur Immunisierung wurden $100 \mu \mathrm{g}$ rrMOG in PBS emulgiert und mit kompletten Freund's Adjuvant (CFA = Inkomplettes Freund's Adjuvant (IFA) + $200 \mu \mathrm{g}$ Hitze inaktiviertes Mycobacterium tuberculosis) im Verhältnis $1 \mathrm{zu} 1$ vermischt. Die intradermale Injektion erfolgte mit $200 \mu \mathrm{l}$ der MOG-Lösung am proximalen Ende des Rattenschwanzes.

\subsubsection{STEREOTAKTISCHE COLLICULUS-INJEKTION}

Vierzehn Tage vor der Immunisierung erfolgte die retrograde Markierung der retinalen Ganglienzellen (RGZ) mit dem fluoreszierenden Farbstoff Fluorogold (FG), um die Dichte dieser Zellen erfassen zu können.

Die Tiere erhielten eine Anästhesie durch intraperitoneale Applikation von Chloralhydrat $(0,42 \mathrm{mg} / \mathrm{kg} \mathrm{KG})$. Der Schädel der Ratten wurde in einem Stereotaxie-Gerät fixiert, um dort einen etwa $3 \mathrm{~cm}$ langen mediosagittalen Hautschnitt durchzuführen. Haut und Bindegewebe wurden entfernt. Auf Höhe der Colliculi superiores, 6,8 mm dorsal und $2 \mathrm{~mm}$ lateral des Bregma, wurde die Schädeldecke perforiert. Stereotaktisch wurden $2 \mu$ der FluorogoldLösung $(5 \%$ in $0,9 \% \mathrm{NaCl})$ in beide Colliculi superiores injiziert. Nach der Behandlung wurde die Operationswunde vernäht.

Das Fluorogold gelangte über retrograden Transport entlang der Axone selektiv in die RGZ, die dadurch durch Fluoreszenzmikroskopie detektierbar wurden und quantifiziert werden konnten. Die Auswertungsmethode zur Dichte der RGZ kann in Paragraph 2.2.10 nachgelesen werden. 


\subsubsection{BEHANDLUNG DER TIERE MIT $\alpha$-RGMA ( $\alpha$-RGMA, $\alpha$-HRGMA, PBS)}

Die 48 Tiere wurden wie in Abschnitt 2.2.1 beschrieben per Zufallsprinzip in sechs Behandlungsgruppen eingeteilt. Die Hochdosis- und die Niedrigdosisgruppe wurden zweimal pro Woche durch intraperitoneale Applikation behandelt. Auch im zweiten Durchlauf des Experimentes erhielten die in zwei Behandlungsgruppen eingeteilten Ratten entsprechend zweimal die Woche das Placebo beziehungsweise das Verum. Die Behandlung wurde am Tag der Immunisierung begonnen und bis zum Tag 14 der Manifestation der Krankheit fortgesetzt.

\subsubsection{BEURTEILUNG DER KLINIK DER TIERE UNTER $\alpha$-RGMA-BEHANDLUNG}

Die Tiere wurden zur Kontrolle des klinischen Verlaufs jeden Tag gewogen und untersucht. Zusätzlich wurde täglich ein Score entsprechend der Tabellen 2.7 und 2.8 erhoben, um einen klinischen Vergleich der Tiere zu ermöglichen.

Tabelle 2.7 Paresen

\begin{tabular}{|l|l|}
\hline \multicolumn{1}{|c|}{ Score } & \multicolumn{1}{c|}{ Klinisches Bild } \\
\hline Grad 0 & Keine Symptome \\
\hline Grad 0,5 & Distale Schwanzparese \\
\hline Grad 1 & Komplette Schwanzparese \\
\hline Grad 1,5 & Schwanzparese und leichte Hinterbeinparese \\
\hline Grad 2 & Einseitige schwere Hinterbeinparese \\
\hline Grad 2,5 & Beidseitige schwere Hinterbeinparese \\
\hline Grad 3 & Komplette beidseitige Hinterbeinparese \\
\hline Grad 3,5 & Komplette beidseitige Hinterbeinparese und Parese der Vorderbeine \\
\hline Grad 4 & Komplette Parese (Tetraplegie), Tod \\
\hline
\end{tabular}

Tabelle 2.8 Schwindel/Ataxie

\begin{tabular}{|l|l|}
\hline \multicolumn{1}{|c|}{ Score } & \multicolumn{1}{c|}{ Klinisches Bild } \\
\hline A1 & Kopfschiefhaltung \\
\hline A2 & Kopfschiefhaltung und Bewegungseinschränkung \\
\hline A3 & Rotation um die eigene Achse \\
\hline
\end{tabular}




\subsubsection{PERFUSION DER RATTEN}

Am Ende des klinischen Experiments erhielten die Ratten eine Überdosis an Kohlenstoffdioxid $\left(\mathrm{CO}_{2}\right)$. Dann wurde ein Loch mit einem Durchmesser von circa 0,5 cm in die linke Herzkammer geschnitten und von dort aus eine Sonde in die Aorta geschoben. Durch diese Sonde konnten die Versuchstiere mit 4 \% Paraformaldehyd (PFA; gelöst in PBS) perfundiert werden. Es folgte die Präparation des Gehirns, des Rückenmarks und der Augen.

\subsubsection{GEWEBEENTNAHME, FIXATION UND HERSTELLUNG DER PARAFFINSCHNITTE}

Kurz nach der Entnahme beider Augenbecher wurde die Retina in PFA freipräpariert und nach vier seitlichen Einschnitten auf einen Objektträger ausgebreitet.

Gehirn und Rückenmark wurden 24 Stunden in $4 \%$ Paraformaldehyd in PBS gelagert und fixiert. Es folgte eine mindestens 24-stündige Inkubation in PBS. Daraufhin konnten die Sehnerven und das Rückenmark präpariert und in vertikaler Lage in Paraffin eingebettet werden. Die fertigen Paraffinblöcke wurden mit dem Mikrotom in 0,5 $\mu$ m dünne Schnitte verarbeitet, welche über Nacht im Brutschrank bei $60{ }^{\circ} \mathrm{C}$ getrocknet und fixiert wurden. Das weitere Vorgehen wird in den Abschnitten der histopathologischen Färbungen beschrieben.

\subsubsection{AUSWERTUNG DER DICHTE DER RETINALEN GANGLIENZELLEN}

Die Auswertung der RGZ-Dichte erfolgte unter dem Fluoreszenzmikroskop mittels eines UV-Filters (365/397 nm) und eines Gitterokulars. Es wurden die durch Fluorogold (FG) markierten Zellen in drei verschiedenen Regionen $\left(62500 \mu \mathrm{m}^{2}\right)$ pro retinalen Quadranten an drei verschiedenen Exzentrizitäten bestimmt. Die drei Exzentrizitäten entsprachen 1/3, 3/6 und 5/6 des retinalen Radius.

Das Auszählen der RGZ wurde am 14. Tag der MOG-EAE und am 35. Tag, falls noch keine Symptomatik zu erkennen war, vorgenommen.

Frühere Untersuchungen bewiesen, dass sich während der Entwicklung einer MOGinduzierten Optikusneuritis die Dichte der RGZ durch apoptotische Vorgänge signifikant reduziert (Meyer et al. 2001). Im Vergleich dazu ist in gesunden Retinae der BN-Ratten eine mittlere Dichte von $2730 \pm 145$ Zellen pro $\mathrm{mm}^{2}$ festgestellt worden (Diem et al. 2003) 


\subsection{HISTOPATHOLOGIE}

Zur Lokalisation von RGMa im ZNS Rattengewebe wurden immunhistochemische Färbungen gegen RGMa an Längs- und Querschnitten des Rückenmarks durchgeführt. Daneben konnte durch vier unterschiedliche Färbungen an Querschnitten des Sehnervens das Ausmaß an Inflammation und axonalen Schaden untersucht werden.

\subsubsection{IMMUNHISTOCHEMISCHE FÄRBUNG}

Immunhistochemische Färbungen beruhen auf der Detektion von spezifischen Antigenen mittels Antikörper. Die Antigene können unterschiedlicher Natur sein. Meist sind es Oberflächenproteine bestimmter Zellen, die anhand dieser Methode durch farbliche Markierung erkannt werden können.

Für sämtliche immunhistochemische Färbungen wurden die Schnitte in einer absteigenden Xylol-Alkoholreihe (zweimal 10 min Xylol $100 \%$ (v/v), zweimal 3 min EtOH $100 \%$ (v/v), je $3 \mathrm{~min}$ in $\mathrm{EtOH} 96$ \% (v/v), EtOH $70 \%$ (v/v), EtOH 50 \% (v/v) entparaffiniert und zunächst in Aqua dest. überführt. Die entparaffinierten Schnitte wurden dreimal für $5 \mathrm{~min}$ in $10 \mathrm{mM}$ Citratpuffer $(0,2 \%, \mathrm{pH} 6,0)$ zur Antigenmaskierung aufgekocht. Nach Abkühlung des Citratpuffers erfolgte für 10 min die Blockierung der endogenen Peroxidase mittels $10 \%$ $\mathrm{H}_{2} \mathrm{O}_{2}$ /PBS-Lösung. Zum Stoppen der Reaktion wurden die Schnitte mit PBS gespült und in Spacer eingelegt. Um weitere unspezifische Bindungsstellen $\mathrm{zu}$ blockieren, wurden die Schnitte für 10 min mit $120 \mu \mathrm{l}$ zehnprozentigem beziehungsweise zwanzigprozentigem Pferdeserum in PBS behandelt. Die Inkubation mit dem Primärantikörper erfolgte über Nacht in der Pferdeserum/PBS-Lösung bei $4{ }^{\circ} \mathrm{C}$.

Am folgenden Tag wurde nach einem dreimaligen Waschvorgang mit PBS der biotinylierte Sekundärantikörper aufgetragen. Eine einstündige Inkubationszeit bei Raumtemperatur (RT) musste dafür eingehalten werden. Danach wurde erneut dreimal mit PBS gewaschen. Eine detaillierte Angabe über die verwendeten Antikörper kann Tabelle 2.6 entnommen werden. Die Schnitte wurden daraufhin mit Avidin-Peroxidase (ABC-Kit; mindestens 30 min vorher angesetzt) eine Stunde lang bei RT behandelt. Nach einem weiteren Waschvorgang mit PBS erfolgte die Entwicklung durch eine ein- bis zehnminütige Inkubation mit Diaminobenzidin (DAB). Diese wurde mit Aqua dest. gestoppt und zur Gegenfärbung 10 min mit Mayer's Hämalaun behandelt. Daraufhin wurden die Schnitte in der aufsteigenden Alkoholreihe (50 \% EtOH bis $100 \%$ EtOH, dann zweimal mindestens 3 min Xylol) entwässert und somit 
konserviert. Abschließend wurde den Objektträgern durch ein nicht-wasserlösliches Eindeckelmedium ein Deckgläschen aufgelegt.

\subsubsection{ED1 ${ }^{+}$-FÄRBUNG}

Anhand der ED1 ${ }^{+}$-Färbung kann in den Sehnervquerschnitten das Ausmaß der Entzündung quantifiziert werden. ED1 wird in lysosomalen Membranen der phagozytierenden Zellen wie Makrophagen und Mikroglia exprimiert und ist während der Phagozytose stark erhöht. Als negative und positive Kontrolle dienten bei dieser Färbung Milzquerschnitte.

Es wurden von jedem Sehnervpräparat Anschnitte aus drei unterschiedlichen Schnitthöhen beurteilt, um das Ausmaß der entzündlichen Infiltration im gesamten Sehnerven möglichst genau erfassen zu können. Die Auswertung der ED1 ${ }^{+}$-Färbung wurde mit dem Mikroskop unter 20-facher Vergrößerung semiquantitativ anhand eines festgelegten Scores durchgeführt.

Tabelle 2.9 ED $1^{+}$-Scoring

\begin{tabular}{|l|l|}
\hline Score & \multicolumn{1}{|c|}{ Definition } \\
\hline 0 & Keine ED1-positiven Zellen \\
\hline 1 & Wenige ED1-positive Zellen in mindestens 1 der 3 Sehnerven-Anschnitte \\
\hline 2 & $\begin{array}{l}10 \text { bis } 50 \% \text { der Fläche infiltriert mit ED1-positiven Zellen in mindestens } \\
1 \text { Sehnerven-Anschnitt }\end{array}$ \\
\hline 3 & $\begin{array}{l}\text { Mehr als 50 \% der Fläche infiltriert mit ED1-positiven Zellen in mindestens } \\
1 \text { Sehnerven-Anschnitt }\end{array}$ \\
\hline
\end{tabular}

\subsubsection{2 $\beta$-APP ${ }^{+}$-FÄRBUNG}

Zum Nachweis von akutem axonalem Schaden wurde die immunhistochemische Färbung gegen $\beta$-APP durchgeführt. $\beta$-APP-positive Zellen manifestieren sich in sogenannten Sphäroiden, welche bis zu 30 Tage erhalten bleiben (Ferguson et al. 1997; Trapp et al. 1998). Kranke Rückenmark-Präparate dienten als negative und positive Kontrolle.

Auch hier wurden von jedem Sehnervpräparat drei verschiedene Schnitthöhen betrachtet. Pro Sehnerv wurde an drei verschiedenen Querschnitten die Anzahl der $\beta$-APP-positiven Zellen am Axioplan Mikroskop ermittelt. Daraus wurde dann der Mittelwert gebildet, um einen möglichst großen Anteil des Sehnervens in der Auswertung zu erfassen. 


\subsubsection{RGMA-FÄRBUNG}

Zur genauen Lokalisation von RGMa-Molekülen im Rückenmark der Ratten diente die immunhistochemische Färbung gegen RGMa. Für diese Untersuchungen wurde Rückenmark als Gewebe ausgewählt, da RGMa im ZNS in den Perikaryen einiger Neurone und im Plexus choroideus exprimiert wird und das Rückenmark im Tiermodell der MOG-EAE ebenfalls entzündliche Läsionen aufweist. Die Expression von RGMa wurde bei Tieren mit EAE im Vergleich zu gesunden Ratten evaluiert.

Um die Prädilektionsstellen von RGMa-Molekülen mit den Arealen der Entzündungsreaktion unter MOG-Immunisierung zu vergleichen, wurde zusätzlich eine ED1 ${ }^{+}$-Färbung von Präparaten, die der gleichen Höhe des Rückenmarks entsprachen, durchgeführt.

\subsubsection{BIELSCHOWSKY-SILBERFÄRBUNG}

Chronischer axonaler Schaden wurde mit der Silberimprägnation neuronaler Strukturen nach Bielschowsky nachgewiesen.

Zunächst wurden die Schnitte in einer absteigenden Xylol-Alkoholreihe (zweimal 10 min Xylol $100 \%$ (v/v), zweimal 3 min EtOH $100 \%$ (v/v), 3 min $\mathrm{EtOH} 96 \%$ (v/v)) entparaffiniert. Es folgte die Inkubation in $20 \%$ Silbernitrat in $\mathrm{dH}_{2} \mathrm{O}$ für 20 min und das Stoppen dieser Reaktion in Aqua dest.. Während des Stoppvorgangs wurde solange Ammoniak der Silbernitratlösung tropfenweise beigefügt, bis der Niederschlag nicht mehr sichtbar war. Daraufhin wurden die Schnitte lichtgeschützt für 15 min in dieser AmmoniakSilberlösung inkubiert. Die Überführung der Schnitte in eine mit Aqua dest. und 3 Tropfen 32-prozentigen Ammoniak gefüllte Küvette beendete diese Inkubation. Zu der AmmoniakSilberlösung wurden 6 bis 8 Tropfen Entwickler hinzugegeben. Daraufhin wurden die Schnitte in dieser Lösung 3 bis 5 min inkubiert, gerade solange, bis die Schnitte schwarz und der Hintergrund grau-braun wurde. Es folgte ein Waschvorgang in Aqua dest., eine zweiminütige Inkubation in $2 \%$ Natriumthiosulfat und ein abschließendes Waschen unter Leitungswasser. Die Präparate wurden in der aufsteigenden Alkoholreihe $(50 \% \mathrm{EtOH}$ bis $100 \% \mathrm{EtOH}$ ) bis hin zum Xylol entwässert und mit nicht-wasserlöslichem Eindeckelmedium eingedeckt.

Die Auswertung erfolgte mikroskopisch bei einer 100-fachen Vergrößerung in Öl-Immersion. Auch hier wurden drei Sehnervanschnitte aus verschiedenen Höhen des Sehnervens betrachtet. Innerhalb jedes Sehnervanschnittes wurden drei verschiedene Blickfelder ausgewertet. Als Hilfsmittel wurde ein Grid, ein spezielles Okular, benutzt, welches das Blickfeld mit einer standardisierten Fläche von $2500 \mu \mathrm{m}^{2}$ in ein bestimmtes Rastermuster 
einteilt und somit die Beurteilung der Axondichte vereinheitlicht. Kreuzte sich ein Axon mit einem kleinen Teilstrich des Grids, wurde 1 Punkt vergeben. Maximal konnten 25 Punkte erreicht werden. Für jeden Sehnerven wurde der Mittelwert errechnet.

\subsubsection{LUXOL-FAST-BLUE-FÄRBUNG}

Die Luxol-Fast-Blue-Färbung (LFB) diente dem Nachweis axonaler Demyelinisierung in Folge von Entzündungsprozessen am Sehnerven. Während intakte Myelinscheiden blau gefärbt wurden, erschienen demyelinisierte Regionen rosa.

Zunächst wurden die Schnitte in der absteigenden Xylol-Alkoholreihe (zweimal 10 min Xylol $100 \%$ (v/v), zweimal 3 min EtOH $100 \%$ (v/v), 3 min EtOH $96 \%$ (v/v) entparaffiniert. Dann erfolgte die Inkubation in der LFB-Lösung über Nacht bei $60{ }^{\circ} \mathrm{C}$.

Am folgenden Tag wurden die Schnitte durch aufeinander folgendes Eintauchen in $90 \%$ EtOH, 0,05\% Lithiumcarbonat, $70 \%$ EtOH und Aqua dest. differenziert, in $1 \%$ Perjodsäure 5 min inkubiert und daraufhin 5 min in Leitungswasser gebläut. Nach kurzem Spülen mit Aqua dest. wurden die Schnitte für $30 \mathrm{~min}$ mit Schiffschem Reagenz inkubiert und anschließend wieder für $5 \mathrm{~min}$ in Leitungswasser gebläut. Um die Zellkerne der Präparate differenzieren zu können, wurden die Schnitte für 7 min mit Mayer's Hämalaun gefärbt. Durch die darauf folgende Reaktion mit Aqua dest. und $\mathrm{HCl}-\mathrm{EtOH}$ wurde der Färbevorgang beendet. Nach kurzer Lagerung in Aqua dest. wurden die Schnitte in der aufsteigenden Alkoholreihe (50\% EtOH bis $100 \%$ EtOH) bis hin zum Xylol wieder entwässert. Die Schnitte wurden mit nicht-wasserlöslichem Eindeckelmedium eingedeckt.

Die Auswertung erfolgte an drei verschiedenen Anschnitten eines Sehnervens, die jeweils repräsentativ eine bestimmte Höhe des Nervs darstellten. Jeweils die Fläche des gesamten Sehnervs und die Fläche des demyelinisierten Teils des Sehnervs wurden mittels der Software Axiovision 4.2 gemessen und in Relation zueinander gesetzt. Abschließend wurde aus den drei Messungen der Mittelwert errechnet und in Prozent angegeben.

\subsection{STATISTISCHE ANALYSEN}

Die statistische Analyse erfolgte mit dem Statistikprogramm GraphPad Prism. Die Versuchsdaten wurden als Mittelwert \pm Standardabweichung angegeben. Zur Beurteilung der statistischen Signifikanz wurde eine einfaktorielle Varianzanalyse (ANOVA) eingesetzt. Im zweiten Experimentansatz erfolgte der statistische Vergleich der zwei Behandlungsgruppen mit dem t-Test. Eine Irrtumswahrscheinlichkeit von $\mathrm{p}<0,05$ wurde als statistisch signifikant 
betrachtet. Alle Tiere, die innerhalb dieses Experimentes behandelt wurden, wurden in die statistische Analyse eingeschlossen. 


\section{ERGEBNISSE}

\subsection{RGMA-EXPRESSION IM ZNS}

Wie bereits in Paragraph 1.3.2 erwähnt, konnte die Arbeitsgruppe Schwab et al. (2005b) bei ihren Untersuchungen an humanen, cerebralen post-mortem-Schnitten, welche nach Hirnverletzungen traumatischer oder ischämischer Genese gewonnen wurden, eine Akkumulation von RGMa in den lädierten Arealen beobachten. Um zu untersuchen, ob eine derartige Akkumulation auch in den entzündlich demyelinisierenden Läsionen des EAEModells auftritt, erfolgte zunächst eine Expressionsanalyse von RGMa an Rückenmarksschnitten von Ratten, die an einer MOG-induzierten EAE erkrankt waren. Die dafür untersuchten Präparate wurden mit Schnitten von gesunden Kontrollen verglichen. Die immunhistochemischen Lokalisationsanalysen gesunder Tiere ergaben eine stärkere Expression von RGMa in der grauen Substanz des Rückenmarks im Vergleich zur weißen Substanz (Abbildung 3.1). Diese grundsächliche Verteilung der Expression von RGMa wurde auch bei kranken EAE-Ratten festgestellt (Abbildung 3.2). Untersuchungen der Zytologie ergaben, dass die prominenteste RGMa-Expression in großen Motoneuronen und Axonen besteht. 


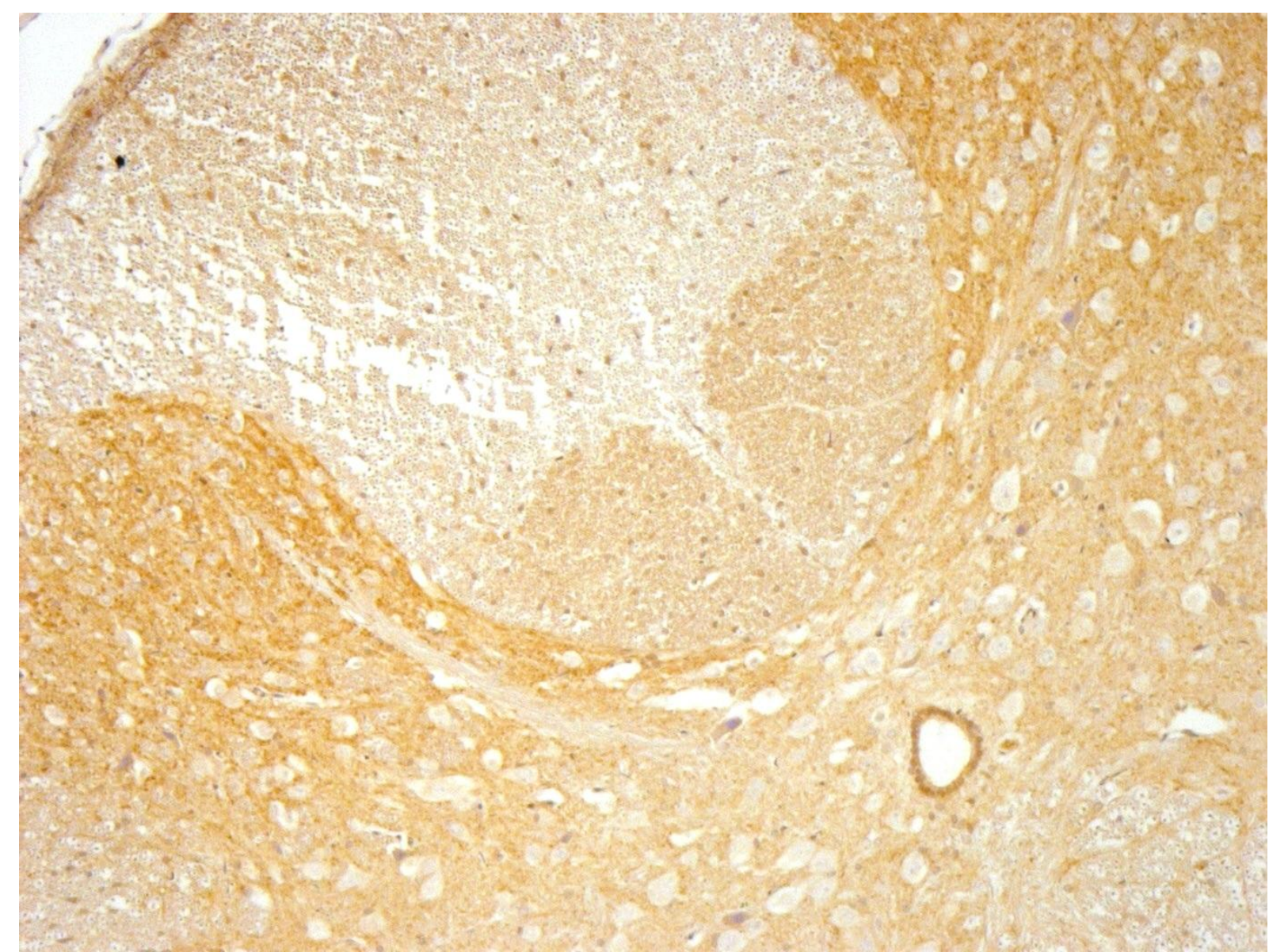

Abbildung 3.1 Die Abbildung zeigt einen Querschnitt des Rückenmarks einer gesunden Ratte. Erkennbar ist eine stärkere Expression von RGMa in der grauen Substanz. Skalierung $100 \mu \mathrm{m}$.

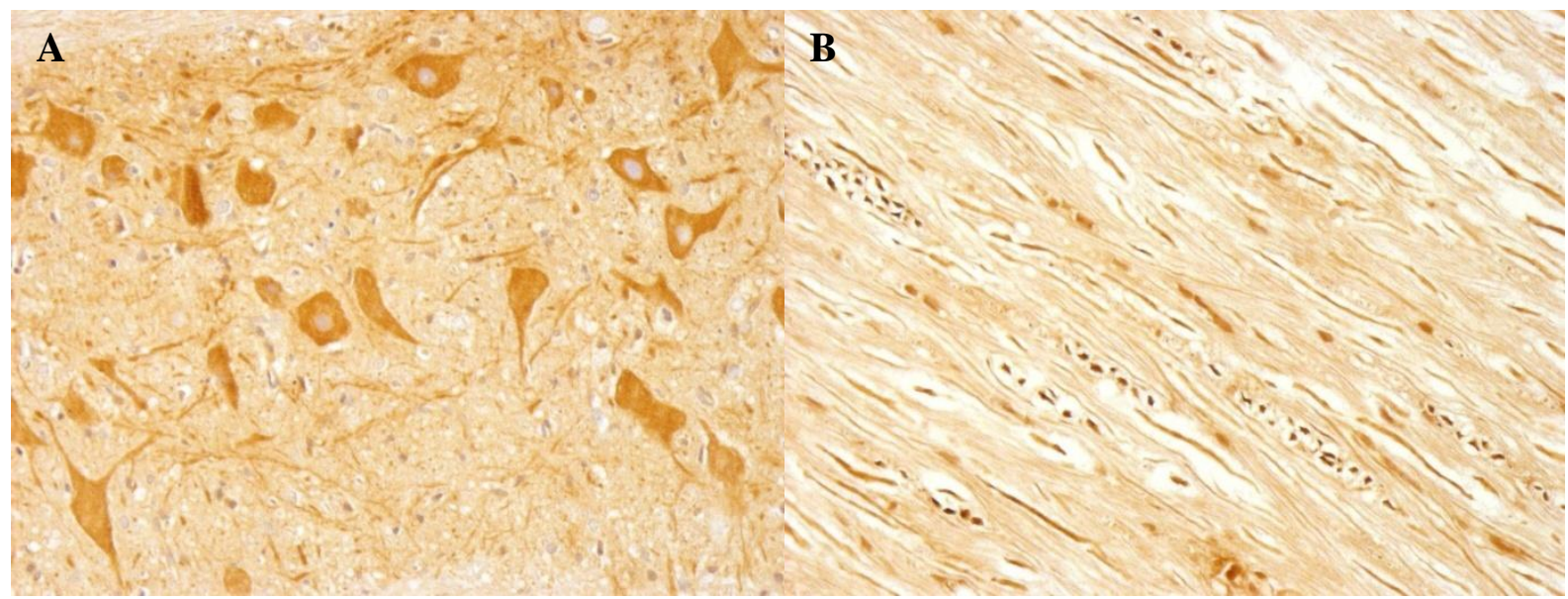

Abbildung 3.2 Färbung gegen RGMa an Rückenmarklängsschnitten der Ratten. (A) zeigt die Expression von RGMa in der grauen Substanz einer EAE-Ratte und (B) lässt die genaue Lokalisation von RGMa-Molekülen in der weißen Substanz einer gesunden Kontrolle erkennen. RGMa ist am deutlichsten in den großen Motoneuronen und Axonen sichtbar. Skalierung $20 \mu \mathrm{m}$. 
Wurden durch MOG-Immunisierung induzierte entzündliche Areale durch ED1 ${ }^{+}$-Färbung sichtbar gemacht und daraufhin mit RGMa gefärbten Rückenmarksschnitten der gleichen Höhe verglichen, konnte eine vermehrte Expression von RGMa in diesen entzündlich infiltrierten Arealen nachgewiesen werden (Abbildung 3.3). Eine solche Betonung der Expression von RGMa in bestimmten Arealen der weißen Substanz wurde in gesunden Kontrollen nicht gefunden und deutet auf eine mögliche Beteiligung des axonlenkenden Moleküls RGMa an der Interaktion von Inflammation und Neurodegeneration in entzündlich demyelinisierenden Läsionen hin.
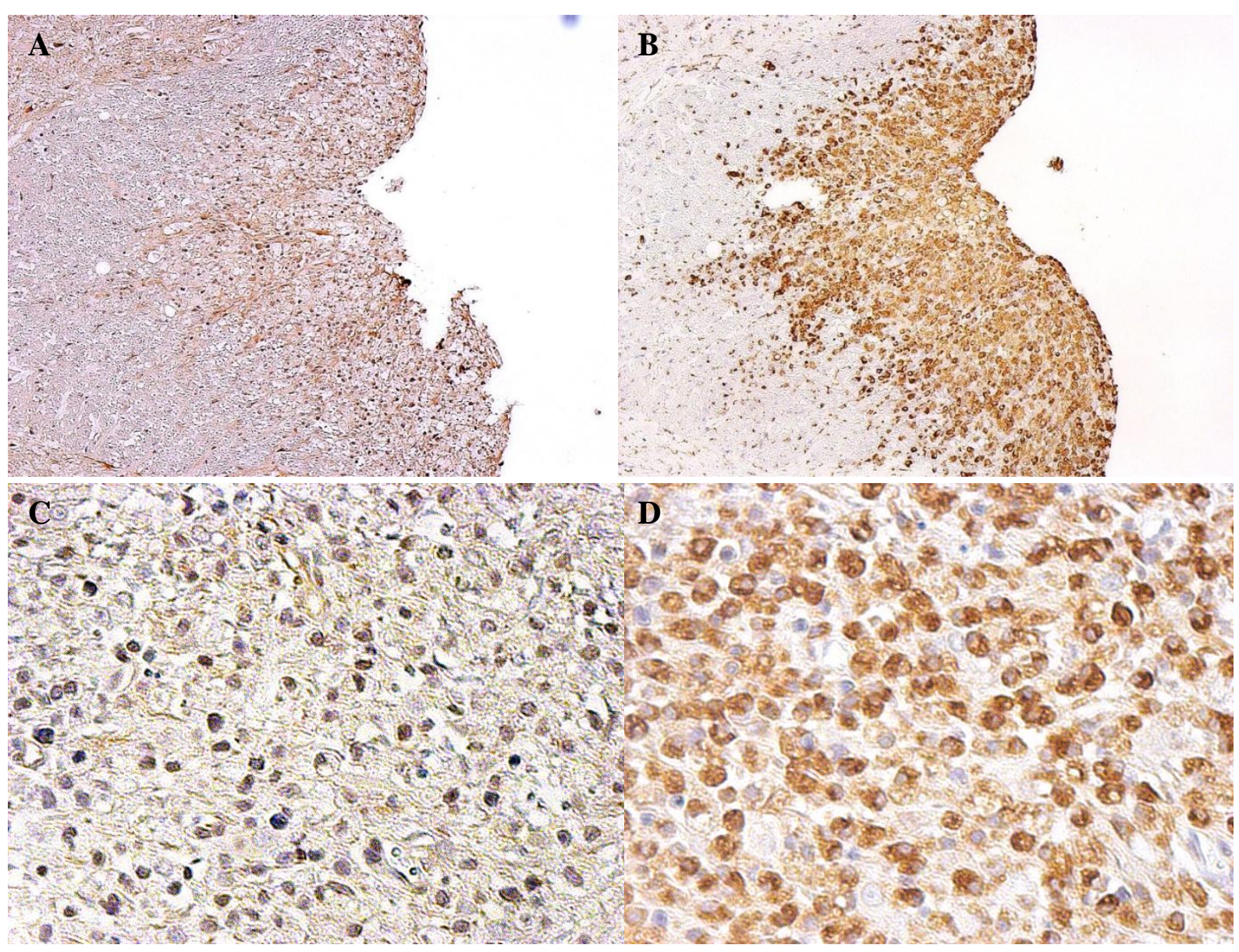

Abbildung 3.3 Färbung gegen RGMa (A) im Vergleich zur ED1-Färbung (B) von Rückenmarksquerschnitten kranker EAE-Ratten zur Evaluation der Expression von RGMa in inflammatorischen Läsionen. Eine Hochregulation in den inflammatorischen Arealen ist zu erkennen. Skalierung: A und B: $100 \mu \mathrm{m}$; $\mathbf{C}$ und $\mathbf{D}: 50 \mu \mathrm{m}$. 


\subsection{KLINISCHE BEURTEILUNG DER $\alpha$-RGMA-BEHANDLUNG}

Durch die intraperitoneale Gabe von einem blockierenden Antikörper gegen RGMa sollte untersucht werden, ob dieser Behandlungsschritt im Tiermodell der MOG-induzierten Optikusneuritis eine axon- oder neuroprotektive Wirkung besitzt. Der dazu benötigte RGMaAntikörper wurde von der Firma Abbott (Ludwigshafen) hergestellt und auf seine Wirksamkeit geprüft. Dabei zeigte der Antikörper in den Konzentrationen von $4 \mathrm{mg} / \mathrm{kg}$ KG und $1 \mathrm{mg} / \mathrm{kg} \mathrm{KG}$ in vivo bei Ratten die beste Aktivität. Die Ratten dieser Versuchsreihe wurden somit in eine Hochdosis- (4 mg/kg KG) und eine Niedrigdosisgruppe (1 mg/kg KG) eingeteilt.

Die Tiere der Hochdosis- sowie die der Niedrigdosisgruppe entwickelten übereinstimmend am Tag 14 nach der Immunisierung eine manifeste EAE. Die Inzidenzrate der EAE betrug in beiden Antikörper-Gruppen der Hochdosisgruppe (Gruppe AK 1: $\alpha$-hRGMa; Gruppe AK 2: $\alpha$-RGMa) $100 \%$, wobei in der Placebogruppe 87,5 \% der Tiere (Gruppe AK 3: PBS; 7 von 8 Tiere) eine klinische Symptomatik entwickelten (Abbildung 3.4A). In der Niedrigdosisgruppe konnte eine manifeste EAE in 87,5 \% der Fälle (bei 7 von 8 Tiere) in der $\alpha$-RGMa-Gruppe, in $100 \%$ der Fälle in der $\alpha$-hRGMa-Gruppe und in $75 \%$ der Fälle (bei 6 von 8 Tiere) der Placebogruppe eine manifeste EAE festgestellt werden (Abbildung 3.4B).

Die Beurteilung der Manifestation der Funktionsdefizite bei den Tieren wurde anhand einer zuvor standardisierten Scoring-Tabelle (siehe Tabelle 2.7 und 2.8) vorgenommen. In der Hochdosisgruppe wurde während der Antikörperbehandlung kein signifikanter Unterschied der klinischen Symptomatik festgestellt. In der Niedrigdosisgruppe wurde an den Tagen 2 bis 5 eine signifikante klinische Verbesserung in der $\alpha$-RGMa-Gruppe verglichen mit der Tiergruppe beobachtet, die den Kontrollantikörper erhalten hatte. Die mit PBS behandelte Placebogruppe verhielt sich dagegen ähnlich wie die $\alpha$-RGMa-Gruppe (Abbildung 3.4B). Dieser Effekt war jedoch am Ende des Experimentes nicht mehr nachzuweisen. 
A

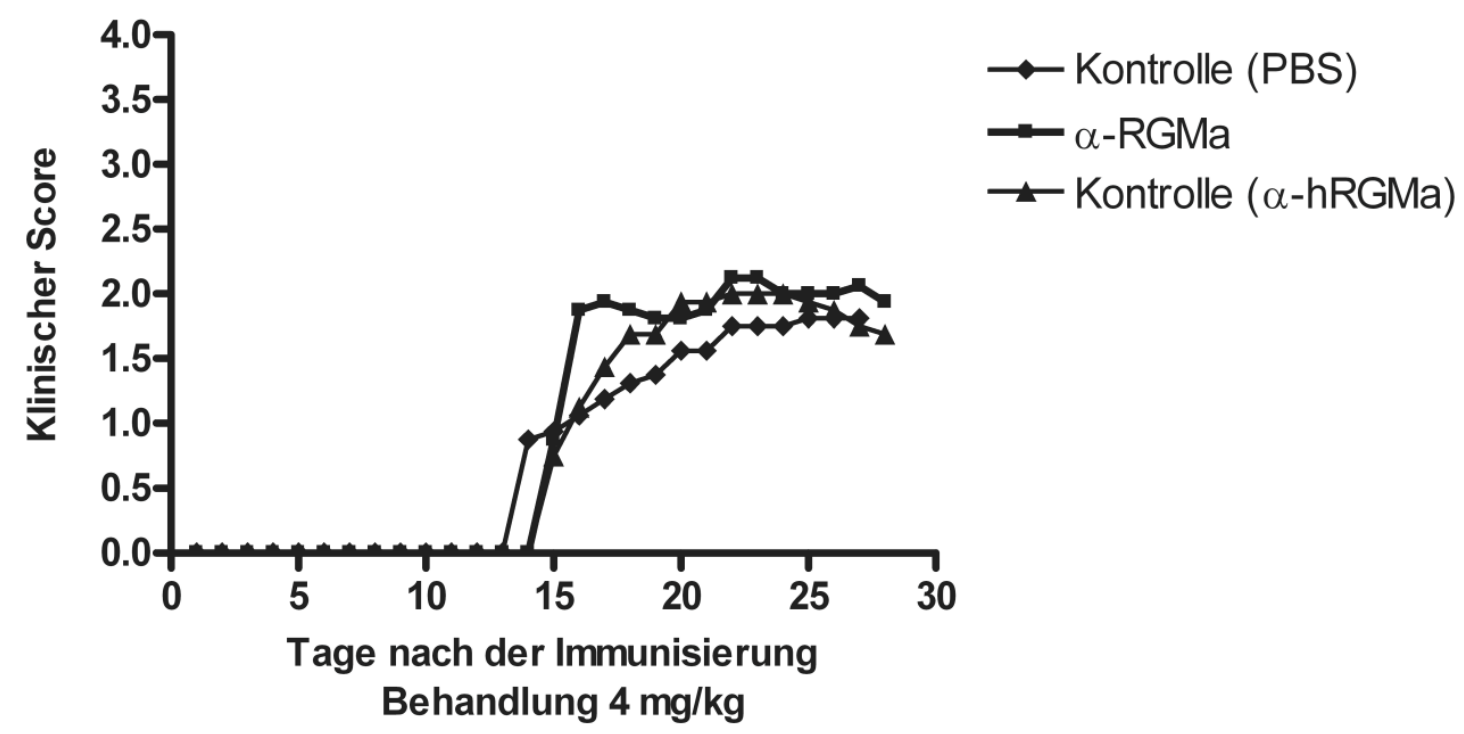

B

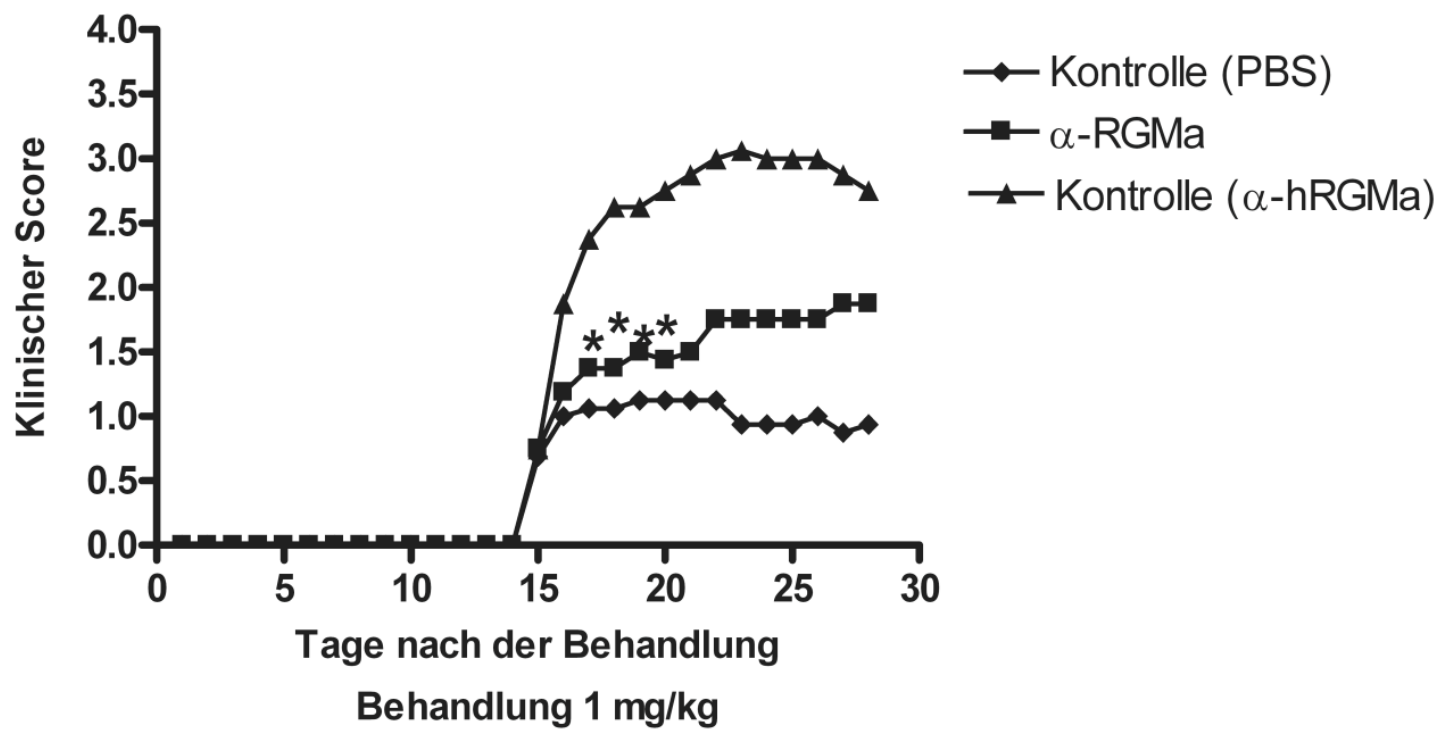

Abbildung 3.4 Graphische Darstellung der klinischen Scores der drei Behandlungsgruppen in der Hochdosis- (A) und der Niedrigdosisgruppe (B). Jede Messung repräsentiert den Mittelwert des neurologischen Scores eines Tages. Um unübersichtliche Datenüberlappungen zu vermeiden, sind keine SEM-Werte aufgeführt. Alle Tiere wurden in die Graphik und die statistische Auswertung eingeschlossen $(p<0,05)$.

Im zweiten Durchgang des Experimentes mit der niedrigen RGMa-Antikörperdosis wurde ein Erkrankungsbeginn am 13. Tag nach der Immunisierung festgestellt. $100 \%$ der Tiere der 
a-RGMa-Gruppe entwickelten eine manifeste EAE, während 87,5\% der Tiere (7 von 8 Tiere) der $\alpha$-hRGMa-Gruppe klinische EAE-Symptome entwickelten.

Auch im zweiten Durchgang erfolgte die klinisch-neurologische Beurteilung anhand des in Tabelle 2.7 und 2.8 aufgelisteten Scores. Es zeichnete sich isoliert am 4. Tag nach der Immunisierung eine signifikante Verbesserung der Klinik in der Tiergruppe ab, die mit dem hRGMa-Antikörper behandelt wurde $(0,44 \pm 0,15$ vs. $1,19 \pm 0,37$; Mittelwert \pm SEM). Am Endpunkt des Experimentes, am Tag 14 der EAE, zeigte sich keine Signifikanz im Vergleich der beiden Behandlungsgruppen (1,31 für hRGMa-Antikörper vs. 1,44 für RGMa-Antikörper; Abbildung 3.2).

Somit findet sich insgesamt keine reproduzierbare signifikante Verbesserung der klinischen Krankheitssymptome bei Applikation des RGMa-Antikörpers verglichen sowohl mit dem Kontrollantikörper, noch im Vergleich zu PBS.

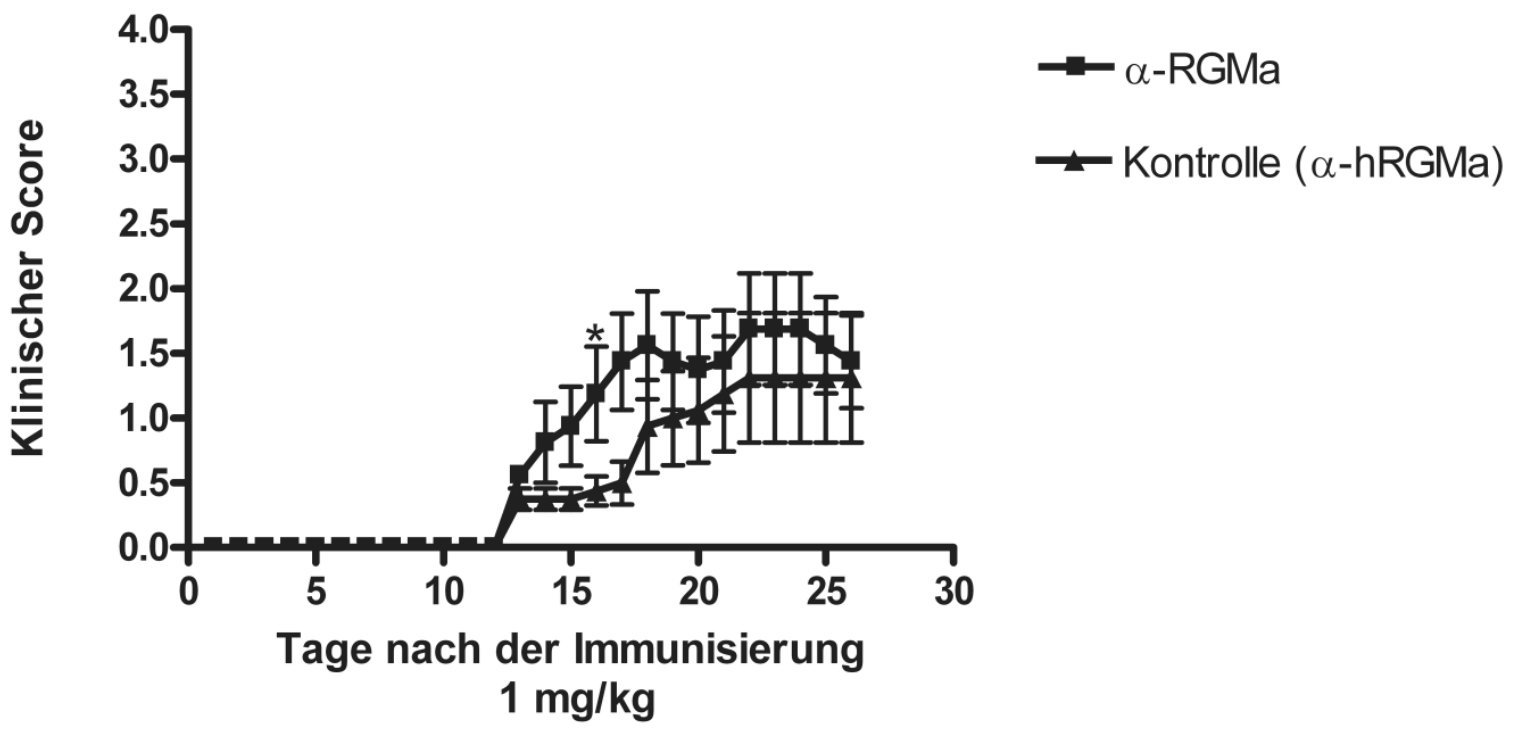

Abbildung 3.5 Graphische Darstellung der klinischen Scores der Behandlungsgruppen im zweiten Durchgang des Experimentes ( $\alpha$-RGMa vs. $\alpha$-hRGMa). Jede Messung repräsentiert den Mittelwert des neurologischen Scores eines Tages. Alle Tiere wurden in die Graphik und die statistische Auswertung eingeschlossen $(\mathrm{p}<0,05)$. 


\subsection{EINFLUSS DER $\alpha$-RGMA-BEHANDLUNG AUF DIE RGZ}

Um den Antikörper $\alpha$-RGMa auf seine potentiell neuroprotektive Wirkung zu untersuchen, wurde in dieser Arbeit unter anderem die Dichte der RGZ ermittelt und unter Berücksichtung der zuvor vorgestellten Beobachtungen (siehe Abschnitt 2.2.10) evaluiert.

In der Hochdosisgruppe konnte nach der Antikörperbehandlung keine verbesserte Zelldichte gefunden werden. Es ergab sich eine mittlere Zelldichte von $851,2 \pm 77,59 \mathrm{RGZ} / \mathrm{mm}^{2}$ in der a-RGMa-Gruppe, von 954,8 $\pm 84,4 \mathrm{RGZ} / \mathrm{mm}^{2}$ in der $\alpha$-hRGMa-Gruppe und von $1134 \pm 152,3 \mathrm{RGZ} / \mathrm{mm}^{2}$ in der Placebogruppe (Abbildung 3.6A). Auch in der Niedrigdosisgruppe konnte keine Verbesserung der Zelldichte unter Antikörperbehandlung nachgewiesen werden: $890,8 \pm 60,5 \mathrm{RGZ} / \mathrm{mm}^{2}$ in der $\alpha$-RGMa-Gruppe, 685,7 $\pm 38,81$ $\mathrm{RGZ} / \mathrm{mm}^{2}$ unter $\alpha$-hRGMa-Behandlung und 887,8 $\pm 106,5 \mathrm{RGZ} / \mathrm{mm}^{2}$ in der Placebogruppe (Abbildung 3.6B).

Die Daten des zweiten Durchgangs des Experimentes wurden entsprechend erhoben und bestätigten die Ergebnisse der vorherigen Zählung (Abbildung 3.7). 
A

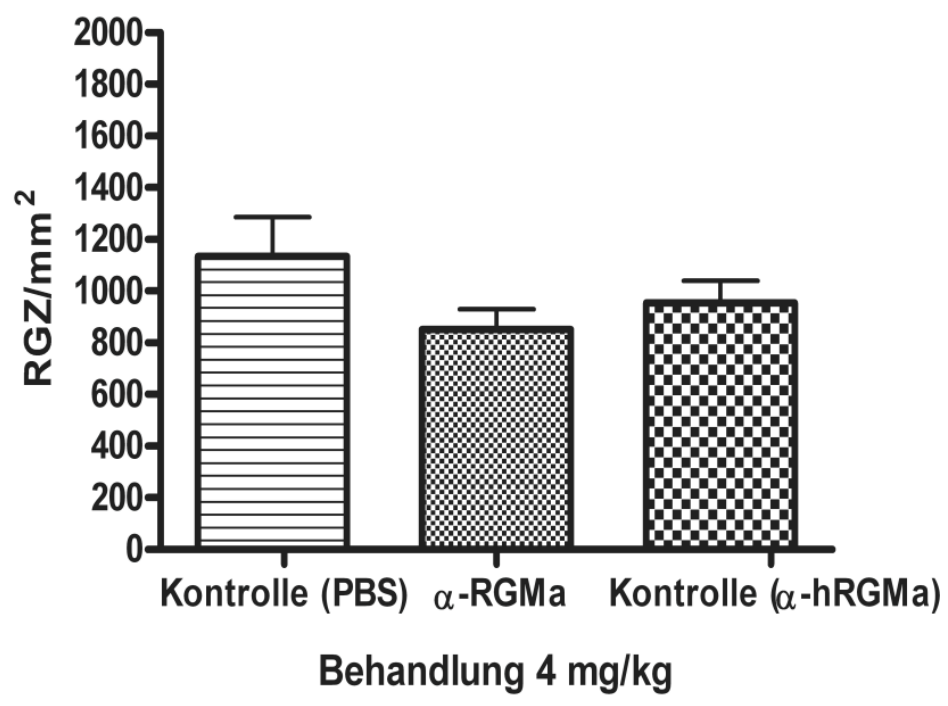

B

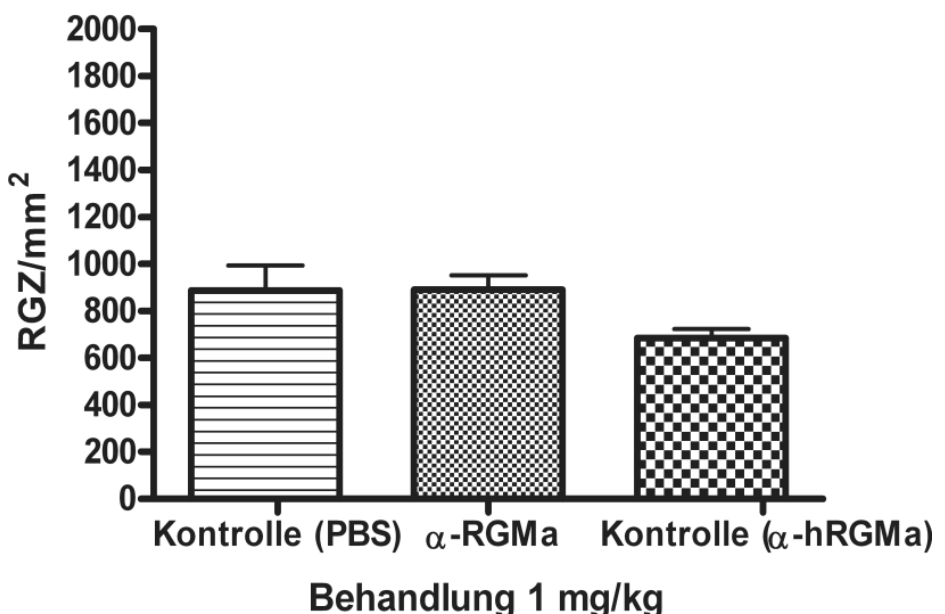

Abbildung 3.6 Graphische Darstellung der RGZ-Dichte in der Hoch- (A) bzw. Niedrigdosisgruppe $(\mathbf{B})$. Die Daten sind als Mittelwerte \pm SEM der Fluorogold markierten Zellen pro $\mathrm{mm}^{2}$ zum 14. Tag nach der Immunisierung dargestellt. 


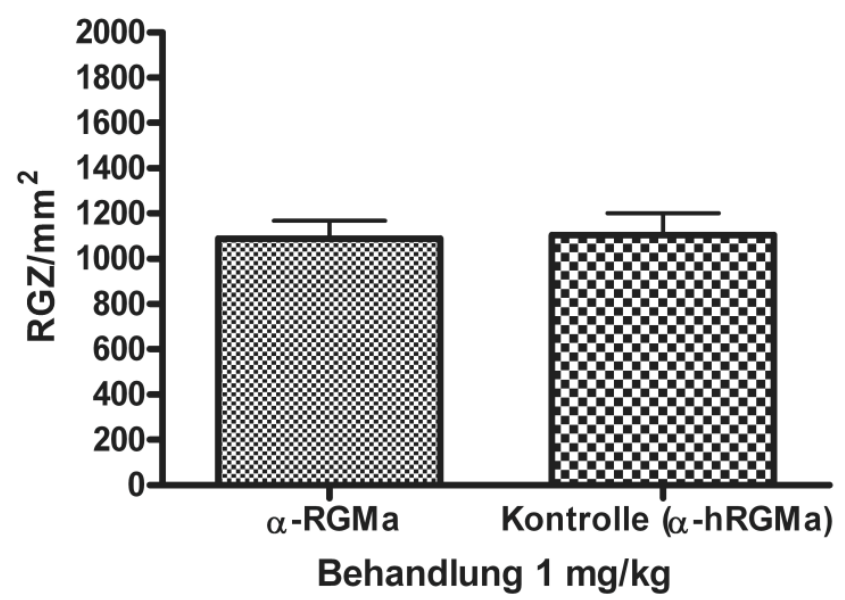

Abbildung 3.7 Graphische Darstellung der RGZ-Dichte in der Niedrigdosisgruppe des zweiten Durchlaufs des Experimentes. Die Daten sind als Mittelwerte \pm SEM der Flourogold markierten Zellen pro $\mathrm{mm}^{2}$ zum 14. Tag nach der Immunisierung dargestellt.

\subsection{HISTOPATHOLOGIE DER SEHNERVEN UNTER $\alpha$-RGMA-BEHANDLUNG}

Zur Beurteilung der Inflammation, Demyelinisierung und Axondegeneration unter $\alpha$-RGMa-Behandlung wurden Sehnervquerschnitte untersucht, da eine sich dort manifestierende Optikusneuritis im Vergleich $\mathrm{zu}$ anderen zentral nervösen Strukturen verhältnismäßig leicht quantifiziert werden kann. Die Ergebnisse der Auswertung der Färbungen können Tabelle 3.1 und 3.2 entnommen werden. Repräsentative Bilder der gefärbten Sehnervenquerschnitte sind in Abbildung 3.8 dargestellt.

Um den Grad der Demyelinisierung in den Sehnervenquerschnitten auszumessen, wurden die Schnitte mit LFB angefärbt. Der Vergleich der Subgruppen der Hochdosisgruppe ( $\alpha$-RGMa; $\alpha$-hRGMa; PBS) ergab keine signifikanten Unterschiede in Anbetracht des Demyelinisierungsgrades. Auch in den Subgruppen der Niedrigdosisbehandlung konnten keine wesentlichen Differenzen im Demyelinisierungsgrad festgestellt werden.

Zur Darstellung des Entzündungsausmaßes wurden aktivierte Makrophagen und Mikroglia in den Querschnitten der einzelnen Sehnerven durch immunhistochemische Färbung gegen ED1 markiert. Es zeigte sich sowohl in der Hochdosis-, als auch in der Niedrigdosisgruppe kein signifikanter Unterschied in der Infiltration mit aktivierten Makrophagen und Mikroglia zwischen Placebogruppen und Verum behandelter Gruppe. 
Um akute Axonschädigungen in diesem Experiment $\mathrm{zu}$ untersuchen, wurden die Sehnervenquerschnitte einer immunhistochemischen Färbung gegen $\beta$ APP unterzogen. $\beta$ APP akkumuliert bei einer Beeinträchtigung des axonalen Transports, sodass axonale Schäden mittels dieser Färbung frühzeitig detektiert werden können. Sowohl in der Hochdosis-, als auch in der Niedrigdosisgruppe konnte durch die RGMa-Antikörperbehandlung im Vergleich zur Placebobehandlung keine signifikante Verbesserung der akuten axonalen Schädigung erreicht werden.

Um die Sehnerven zusätzlich auf chronische axonale Schädigung zu untersuchen, wurden die Axone mittels Bielschowsky-Silberimprägnation sichtbar gemacht. Die Auszählung erfolgte unter dem Mikroskop durch ein Grid. Die genaue Vorgehensweise kann in Abschnitt 2.3.3 nachgelesen werden. Die ermittelten Werte wurden in Relation zu gesunden Kontrollen gestellt. Ein signifikanter Unterschied konnte nicht festgestellt werden. Auch in der Niedrigdosisgruppe konnte keine Verbesserung der Axondichte nachgewiesen werden.

Insgesamt konnte somit bei der histopathologischen Untersuchung der Sehnerven kein Unterschied zwischen Ratten mit $\alpha$-RGMa-Behandlung und Kontrolltieren nachgewiesen werden. Alle Daten, die im zweiten Durchlauf des Experimentes ermittelt wurden, bestätigten die in den vorherigen Abschnitten aufgelisteten Ergebnisse der Färbungen. 
Tabelle 3.1 Histopathologie der Sehnerven unter Hochdosisbehandlung (4 mg/kg KG). Es wurden keine Signifikanzen ermittelt.

\begin{tabular}{|l|l|l|l|l|}
\hline Tiergruppe & $\begin{array}{l}\text { Prozent der } \\
\text { Demyelinisierung }\end{array}$ & $\begin{array}{l}\text { Infiltrierende } \\
\text { ED1+-Zellen } \\
\text { (Score) }\end{array}$ & $\begin{array}{l}\text { Anzahl der } \\
\beta \text {-APP+-Zellen }\end{array}$ & $\begin{array}{l}\text { Axondichte }(\% \text { der } \\
\text { gesunden } \\
\text { Axondichte })\end{array}$ \\
\hline$\alpha$-RGMa & $40,08 \pm 5,59$ & $2,33 \pm 0,21$ & $6,97 \pm 1,12$ & $69,71 \pm 2,85$ \\
\hline$\alpha-$ hRMa & $40,31 \pm 6,33$ & $2,31 \pm 0,18$ & $8,77 \pm 1,48$ & $75,67 \pm 2,37$ \\
\hline PBS & $27,76 \pm 3,47$ & $2,38 \pm 0,18$ & $9,16 \pm 1,28$ & $75,75 \pm 3,6$ \\
\hline
\end{tabular}

Tabelle 2 Histopathologie der Sehnerven unter Niedrigdosisbehandlung (1 mg/kg KG). Auch hierbei wurden keine signifikanten Unterschiede beobachtet.

\begin{tabular}{|l|l|l|l|l|}
\hline Tiergruppe & $\begin{array}{l}\text { Prozent der } \\
\text { Demyelinisierung }\end{array}$ & $\begin{array}{l}\text { Infiltrierende } \\
\text { ED1+-Zellen } \\
\text { (Score) }\end{array}$ & $\begin{array}{l}\text { Anzahl der } \\
\beta \text {-APP+-Zellen }\end{array}$ & $\begin{array}{l}\text { Axondichte }(\% \text { der } \\
\text { gesunden } \\
\text { Axondichte })\end{array}$ \\
\hline$\alpha$-RGMa & $37,81 \pm 6,35$ & $2,43 \pm 0,25$ & $9,86 \pm 0,78$ & $76,07 \pm 3,41$ \\
\hline$\alpha$-hRGMa & $33,25 \pm 2,55$ & $2,33 \pm 0,14$ & $10,47 \pm 0,55$ & $70,99 \pm 1,78$ \\
\hline PBS & $34,42 \pm 6,32$ & $1,92 \pm 0,26$ & $9,27 \pm 0,73$ & $78,75 \pm 3,16$ \\
\hline
\end{tabular}



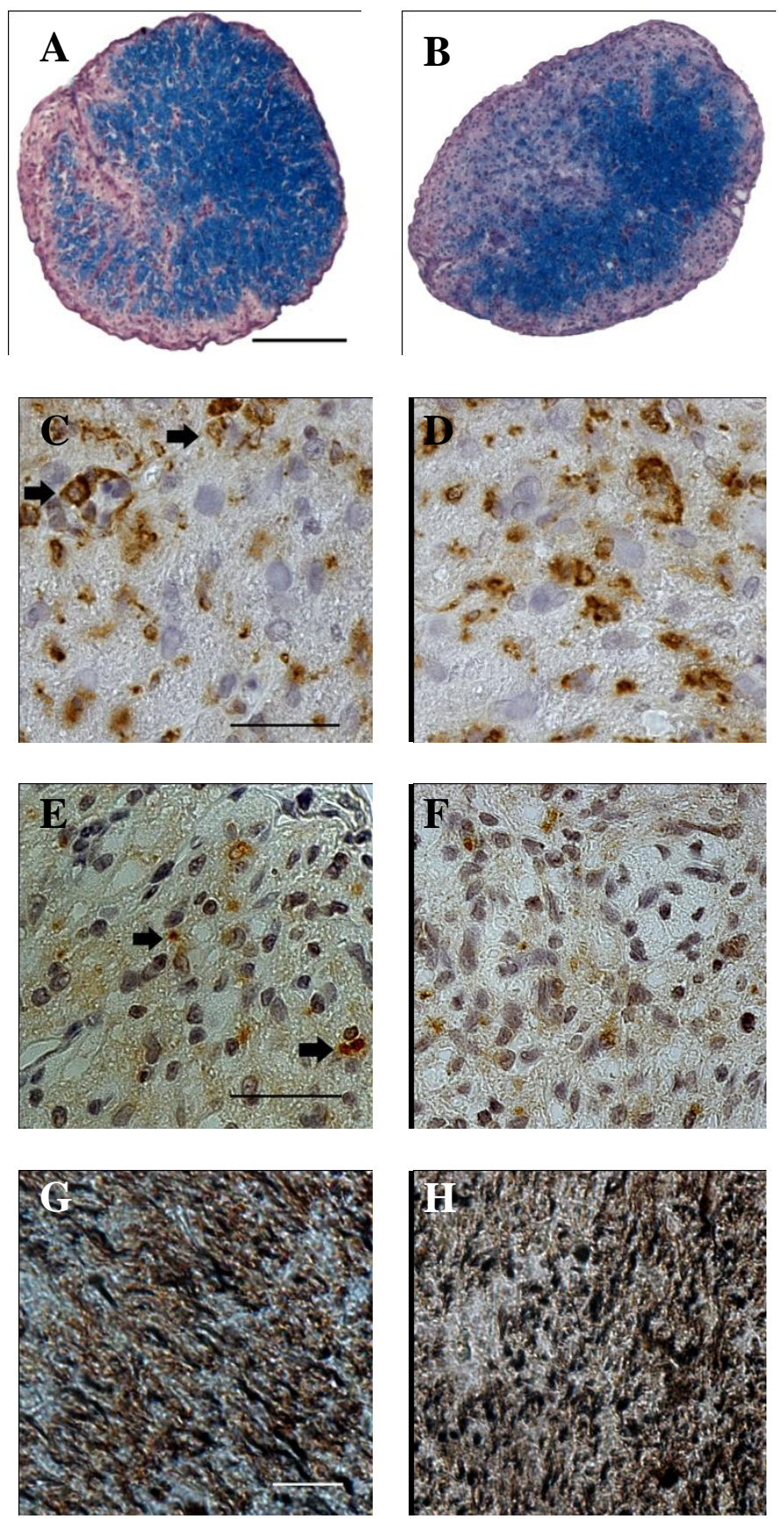

Abbildung 3.8 Histopathologie der Sehnerven. Dargestellt sind repräsentative Sehnervenquerschnitte von Ratten unter $\alpha$-RGMa- (A, C, E, G) und unter Placebobehandlung (B, D, F, H). Bei der Auswertung der vier Färbungen konnte kein signifikanter Unterschied zwischen $\alpha$-RGMa- und Placebobehandlung gefunden werden. A, B) Die Luxol-Fast-Blue-Färbung wurde zur Bestimmung des Ausmaßes an Demyelinisierung benutzt. Skalierung $100 \mu \mathrm{m}$. C, D) Die Anzahl an Makrophagen und aktivierten Mikrogliazellen wurde anhand der immunhistochemischen ED1 ${ }^{+}$-Färbung bestimmt. Die Pfeile zeigen auf ED1-positive Zellen. Skalierung $50 \mu \mathrm{m}$. E, F) Anhand der immunhistochemischen $\beta$-APP ${ }^{+}$-Färbung konnte akuter axonaler Schaden nachgewiesen werden. Die Pfeile weisen auf $\beta$-APP-positive Zellen. Skalierung $50 \mu \mathrm{m}$. G, H) Die Axondichte im Sehnervenquerschnitt wurde anhand der Bielschowsky-Silberimprägnation sichtbar gemacht. Skalierung $20 \mu \mathrm{m}$. 


\section{DISKUSSION}

Die MS ist eine chronische Erkrankung des ZNS, der histologisch diffus über die graue und weiße Substanz verteilte entzündliche Läsionen zugrunde liegen (Storch et al. 1998a; Kutzelnigg et al. 2005). Die Entzündungsaktivität ist von einem voranschreitenden neuronalen und axonalen Schaden begleitet, welcher aufgrund seiner Irreversibilität nicht nur für den Patienten und den Arzt, sondern auch für die Forschung von besonderer Bedeutung ist. Die progressive Neurodegeneration wird inzwischen als Hauptursache bleibender Behinderungen bei MS-Patienten angesehen (Davie et al. 1995; De Stefano et al. 1998; Wujek et al. 2002). Dennoch zielen alle derzeit etablierten Therapien auf die Eindämmung der Inflammation $a b$, wobei die Wirkung dieser Behandlungskonzepte auf chronisch progrediente Krankheitsverläufe gering ist (Kleinschnitz et al. 2007). In diesen Krankheitsstadien kommt es zu einer langsam zunehmenden Neurodegeneration, die die stetige Behinderungsprogression unabhängig von der aktuellen entzündlichen Aktivität hervorruft. Bislang ist keine Möglichkeit der therapeutischen Neuroprotektion vorhanden, jedoch scheint dies ein viel versprechender Ansatz zur Prophylaxe persistierender neurologischer Defizite bei MS-Patienten zu sein.

In der vorliegenden Arbeit wurde erstmalig die Applikation eines Antikörpers gegen das Molekül RGMa auf eine gleichzeitige neuroprotektive und anti-inflammatorische Wirkung untersucht. Dabei zeigte sich, dass weder der klinische Krankheitsverlauf der MOGinduzierten Optikusneuritis noch die entzündliche Infiltration, Demyelinisierung oder der axonale und neuronale Schaden durch die Applikation verschiedener Dosierungen von $\alpha$-RGMa verringert werden konnte.

\subsection{EVALUATION DES MOG-INDUZIERTEN EAE-MODELLS}

Aufgrund der schlechten Zugänglichkeit des ZNS und des bis heute lückenhaften Verständnisses über die Pathogenese der MS hat das EAE-Modell für die derzeitige MS-Forschung eine besondere Bedeutung. Die EAE zeichnet sich unter anderem durch ein breites Spektrum an MS-ähnlichen histopathologischen und klinischen Grundzügen aus. Durch die unterschiedliche Auswahl der Dosis, der Methode der Immunisierung und durch den Gebrauch verschiedener Rattenstämme kann das histologische Bild der Läsionen und das Profil klinischer Symptome einer EAE moduliert werden und eröffnet damit die Möglichkeit, unterschiedliche Beschwerden oder Verlaufsformen der MS je nach Ausrichtung der Studie 
zu imitieren (Ben-Nun et al. 1981; Storch et al. 1998a; Gold et al. 2006; Steinman und Zamvil 2006).

Für die vorgelegte Studie wurde das MOG-induzierte EAE-Modell an weiblichen Ratten vom Stamm Brown Norway verwendet. Die MOG-induzierte EAE zeigt eine weitgehende Übereinstimmung der Pathologie, Klinik und zum Teil auch der Immunologie mit der MS, da nicht nur die T-Zell-vermittelte, sondern auch die humorale Immunantwort der MS reflektiert wird (Kornek et al. 2000). Die humorale Immunreaktion nach EAE-Induktion führt zu einer ausgeprägten Entmarkung der Myelinscheiden (Linington et al. 1993) und imitiert somit das pathologische Bild der MS wesentlich besser als ältere Modelle (Gold et al. 2006). Zudemund dies ist gerade für Untersuchungen der Neurodegeneration dieser Erkrankung essentiellist die akute Phase der axonalen Destruktion in aktiv demyelinisierenden MS-Läsionen in sehr ähnlicher Ausprägung bei dieser EAE wieder zu finden (Kornek et al. 2000).

Die Immunisierung durch MOG führt in $90 \%$ der Fälle bei weiblichen BN-Ratten zur Optikusneuritis, einem sehr häufigen Symptom bei Erstmanifestation der MS (Storch et al. 1998b). Die anatomischen Gegebenheiten der Sehbahn erlauben eine separate Untersuchung der Sehnerven sowie die Beurteilung der zugehörigen Neurone, der RGZ. Die Möglichkeit einer selektiven Anfärbung der RGZ mittels eines fluoreszierenden Farbstoff vereinfacht gleichermaßen die Identifikation der RGZ und die quantitative Beurteilung des neuronalen Zellverlustes (Meyer et al. 2001).

Auf der Suche nach neuen Therapieoptionen sind die experimentellen Untersuchungen im Labor Grundlage jeglicher Medikamenteneinführung. Für die MS-Therapie hat sich die EAE als Grundbaustein der präklinischen Phase in der Vergangenheit sehr bewährt (Steinman und Zamvil 2006). Drei der sechs heute fest etablierten MS-Medikamente (Mitoxantron, Glatirameracetat und Natalizumab) wurden vorerst im EAE-Modell erprobt und bewiesen sich dabei als wirksam. Zusätzlich zeigten Vorarbeiten in diesem Rattenmodell mit autoimmuner Optikusneuritis eine gute anti-inflammatorische Wirkung von Interferon- $\beta$ und Methylprednisolon, zwei Standardbehandlungen der MS (Diem et al. 2003; Maier et al. 2006; Sättler et al. 2006). Allerdings fehlt bei diesen Therapien trotz Verringerung von entzündlichem Infiltrat, Demyelinisierung und axonalem Schaden eine Wirkung auf die visuellen Funktionen der Tiere, bedingt durch das unverändert geringe Überleben der RGZ in der Retina. Dagegen hemmt die Behandlung mit Epo die Apoptosemechanismen der Nervenzellen. Das Entzündungsausmaß kann dabei jedoch nicht beeinflusst werden. Erst durch die Kombination der anti-inflammatorischen Behandlung mit einer neuroprotektiven Therapiestrategie wie zum Beispiel mit Epo gelingt es, eine relevante Verbesserung des 
Sehvermögens der Ratten zu erzielen (Diem et al. 2005; Sättler et al. 2008b). Die Ursache dafür ist ein vermehrtes Überleben der RGZ bei gleichzeitigem Erhalt ihrer Axone im Verlauf des Nervus opticus. Inzwischen wird die Wirkung von Epo als Ergänzung zu einer Standardbehandlung mit Methylprednisolon in einer klinischen multizentrischen Phase-II-Studie untersucht (VisionProtect-Studie; PD Dr. med. Ricarda Diem; Universitätsklinikum Homburg/Saar).

Da das Molekül RGMa als Lenkmolekül die retinotektale Projektion von retinalen Ganglienzellen beeinflusst und somit dort eine Expression von funktionsfähigen RGMa-Molekülen gesichert ist (Monnier et al. 2002), erschien es sinnvoll, den Fokus dieser Arbeit auf die Untersuchung der Optikusneuritis der EAE zu legen.

Es sollte nicht vergessen werden, dass das Modell der EAE die komplexe und nur teilweise ätiologisch entschlüsselte Erkrankung der MS nur zu einem gewissen Grad widerspiegelt. Durch diese bruchstückenhafte Erfassung dürfen Ergebnisse nicht unkritisch auf den Menschen übertragen und die endgültige Relevanz experimenteller Befunde muss in der klinischen Forschung bewiesen werden.

Einige Unzulänglichkeiten des EAE-Modells liegen auf der Hand und sollten somit nicht unbeachtet bleiben:

1. fehlende Reproduktion von progredienten Verläufen der Erkrankung

2. für die MS untypische Stimulierung des Immunsystems außerhalb des ZNS

3. unbeschränkte Verweildauer des Immunogens am Immunisierungort

Der klinische Verlauf der MOG-induzierten Optikusneuritis unterscheidet sich in einigen Punkten von dem der MS (Friese et al. 2006). Im EAE-Modell ist das Vorkommen von fulminanten Verläufen, bis hin zum schnellen Tod des Versuchstieres, nicht ausgeschlossen. Zudem ist kein Modell vorhanden, das den primär progressiven Verlauf widerspiegelt (Gold et al. 2006). Meist stellen die Versuchstiere eine genetisch homogene Populationen dar und verfehlen damit eine Imitation der offensichtlichen genetischen Heterogenität der MS. Durch die gleichzeitige Evaluation verschiedener Modelle der EAE könnte dem entgangen werden. Diese Methode beweist sich jedoch als sehr aufwändig und wird in der Praxis daher kaum angewandt.

Das Prinzip der subkutanen Applikation des Immunogens ist in jeder Hinsicht ein artifizieller Vorgang, der eine Immunreaktion von Organen jenseits des ZNS potentiell mit einschließt. Auch hat das Immunogen bedingt durch das beigefügte Adjuvanz eine praktisch unbeschränkte Verteildauer an dem vom ZNS entfernt gelegenen Immunisierungsort und 
sorgt damit für eine ständige und heftige immunologische Stimulierung. Für die MS gibt es keine vergleichenden Ansatzpunkte, die verdeutlichen, dass ZNS Antigene außerhalb des ZNS in immunogener Form vorliegen (Poeck und Hacke 1998; Gold et al. 2006). Vor einigen Jahren wurden Modelle der EAE entwickelt, die nicht auf diese Art der Immunisierung angewiesen sind (Waldner et al. 2000; Zehntner et al. 2003). Dabei ist jedoch der transgene Ansatz der Modelle auch als artifiziell zu betrachten.

Insgesamt ist das EAE-Modell trotz der offensichtlichen Grenzen in der Übertragbarkeit auf die menschliche Erkrankung ein exzellentes Utensil, um die grundlegenden Mechanismen der Entzündung und des immunologisch getriggerten Gewebeschadens des ZNS zu untersuchen. Zusätzlich erlaubt das Modell die Evaluation von neuen Wirkstoffen und dessen Effekt. Bis die Pathogenese der MS nicht endgültig aufgedeckt ist, wird die EAE ihre wesentliche Bedeutung in der MS-Forschung sicherlich nicht verlieren, jedoch sollten bei ihrer Anwendung die Grenzen des Modells nicht vergessen werden.

\subsection{THERAPIEN MIT MONOKLONALEN ANTIKÖRPERN}

Ein Antikörper als essentieller Bestandteil des Immunsystems besteht aus zwei identischen leichten und zwei identischen schweren Ketten, die durch kovalente Bindungen ypsilonartig verbunden sind. Jeweils eine leichte und eine schwere Kette bilden die variable Region, welche als zielgerichtete Bindungsstelle agiert. Die konstante Region beschreibt das Endstück der zwei parallel gelegenen schweren Ketten. Sie kontrolliert unter anderem die Komplementbindung und die durch den Antikörper gesteuerte Zytotoxizität.

Vor einigen Jahrzehnten entstand der Versuch, Erkrankungen, vor allem solche mit autoimmunem Mechanismus, mit polyklonalen Antikörper enthaltenden Immunseren, die in anderen Spezies entwickelt wurden, zu therapieren. Jedoch wurde diese Therapie aufgrund der Unspezifität der Antikörper und der beschränkten Kompatibilität des Immunsystems zwischen tierischem Spender und menschlichem Empfänger meist von einer heftigen allergischen Reaktion begleitet. Die Einführung der monoklonalen Antikörper (MAbs) durch Kohler und Milstein im Jahre 1975 revolutionierte viele Forschungsbereiche, so auch den der Medizin. Inzwischen ist es möglich, Antikörper zu kreieren, die zu $90 \%$ aus humanen Molekülen bestehen, und damit die Immuntoxizität erheblich zu vermindern (Queen et al. 1989). Einzelne, pathophysiologisch relevante Moleküle können durch MAbs zielgerichtet blockiert werden. Vor allem zur Behandlung von Tumorerkrankungen und von 
Autoimmunerkrankungen sowie zur Unterdrückung einer Transplantatabstoßung sind MAbs als therapeutisches Werkzeug nicht mehr weg zu denken. So wird beispielsweise Rituximab, ein chimärer $\mathrm{MAb}$, zur Behandlung eines Non-Hodgin-Lymphoms regelmäßig eingesetzt (Dundar et al. 2009). Ein weiteres Beispiel ist der humanisierte MAb Daclizumab, der bei Transplantatabstoßungen Verwendung findet (Rainiene et al. 2007).

Auch die MS Forschung ließ die Einführung der MAbs nicht unberührt. Mittlerweile steht der MAb Natalizumab als zugelassene Monotherapie bei hochaktiver schubförmiger MS zur Verfügung (Rose et al. 2009). Natalizumab richtet sich gegen die Untereinheit $\alpha_{4}$-Integrin des VLA-4-Rezpetors (very late antigen-4), welcher auf der Oberfläche von Lymphozyten zu finden ist. Die Blockade hindert Lymphozyten daran, eine Bindung mit Adhäsionsmolekülen der Endothelzellen der Blut-Hirn-Schranke (BHS) einzugehen (Simmons 2005). Folge ist eine verminderte Invasion von aktivierten Lymphozyten in das ZNS und somit eine Reduktion von überschießenden Immunreaktionen. Die positiven Effekte der experimentellen Untersuchungen bestätigten sich in den darauf folgenden klinischen Studien (Yednock et al. 1992). Unter Therapie von Natalizumab zeigt sich eine signifikante Verminderung von im MRT nachgewiesenen Läsionen (Miller et al. 2007). Die Schubrate und der EDSS-Parameter (Expanded Disability Status Score)- eine Leistungsskala, die Auskunft über den Schweregrad der Behinderung bei MS gibt- konnten durch Natalizumab deutlich verbessert werden (Polman et al. 2006). Allerdings zeigt auch dieser MAb trotz überzeugender antiinflammatorischer Wirkung keine maßgebliche Verbesserung der Symptomatik bei chronisch progredienten Krankheitsverläufen der MS, die überwiegend durch die fortschreitende Neurodegeneration hervorgerufen wird. Neben Natalizumab werden in der MS-Forschung momentan die MAbs Rituximab (Cross et al. 2006; Petereit et al. 2008), Daclizumab (Bielekova et al. 2006) und Alemtuzumab (Warnke et al. 2009) in klinischen Studien evaluiert.

Eine Anwendung von MAbs sollte vorerst klinischen MS-Zentren vorbehalten werden, da es zu erheblichen Nebenwirkungen kommen kann (Rose et al. 2009). Unter Anwendung von Natalizumab entwickelte sich bei drei von 3300 Patienten eine progressive multifokale Leukenzephalie (PML; Gold et al. 2007). Untersuchungen zur Klärung eines Zusammenhangs zwischen der Behandlung von Natalizumab und dem Auftreten dieser opportunistischen Infektion haben bisher keine schlüssige Erklärung bringen können. So müssen weitere Langzeitstudien folgen, um das Nebenwirkungsprofil einer derartigen Behandlung in Bezug auf die Erkrankung abwägen zu können. Aus diesem Grunde sollte die Indikation einer MAbTherapie bei MS nur bei sorgfältig ausgewählten Patienten gestellt werden. 
Die Entwicklung monoklonaler Antikörper als therapeutisches Werkzeug ist in den letzten Jahren zu einem der am stärksten expandierenden Bereiche in der Arzneimittelforschung geworden. Die Behandlungsmöglichkeiten zahlreicher neoplastischer und chronisch entzündlicher Erkrankungen wurden dadurch deutlich erweitert. Dabei ermöglicht die Gentechnik eine derartige Modifikation der Antikörper und der von ihnen abgeleiteten Moleküle, dass sie in Hinblick auf ihre Spezifität und Affinität zielgerichtet und abgestimmt auf den Pathomechanismus der Erkrankung entwickelt werden können. Es bleibt abzuwarten, ob in Zukunft die Entwicklung eines MAbs gelingen wird, der spezifisch auf die Interaktion von Inflammation und Neurodegeneration bei der MS abzielt und beide Aspekte dieser Erkrankung durch eine Monotherapie behandelbar macht.

\subsection{NEUROPROTEKTIVE ERGÄNZUNGSBEHANDLUNGEN}

Während bis vor einem Jahrzehnt hauptsächlich der entzündliche Prozess im Mittelpunkt der Arzneimittelentwicklungen bei MS stand, wird nun zunehmend versucht, Therapiestrategien $\mathrm{zu}$ erarbeiten, die gegen die neurodegenerative Komponente dieser Erkrankung zielen. Dem zugrunde liegen pathophysiologische Ergebnisse, die nicht nur auf die inflammatorischen Vorgänge, sondern auch auf eine fortschreitende Axondegeneration innerhalb früher MS-Läsionen hinweisen (Ferguson et al. 1997). Zusätzlich ist nachgewiesen geworden, dass der Verlust von intakten Axonen mit dem Behinderungsgrad von MS-Patienten korreliert (Matthews et al. 1998; Bjartmar und Trapp 2001; De Stefano et al. 2007). Diese Erkenntnisse haben zur Folge, dass die bisherigen ausschließlich anti-inflammatorischen Therapiekonzepte als unzureichend angesehen werden können. Durch Medikation können bleibende Behinderungen der MS-Patienten bis zum heutigen Zeitpunkt nur begrenzt hinausgezögert werden. Der primär progrediente Verlauf der Erkrankung ist bisher nur bedingt therapeutisch beeinflussbar. Neuroprotektive Behandlungsstrategien - bestenfalls in Kombination mit einer anti-inflammatorischen Therapie - würden eine erhebliche Erweiterung des therapeutischen Spektrums bedeuten. Die klinischen Zeichen eines Schubes, die als Vorbote einer größeren irreversibel verlaufenden ZNS-Schädigung angesehen werden können, und der langjährige chronische Verlauf der Erkrankung prädestinieren für ein gutes Ansprechen einer neuroprotektiven Behandlungsmaßnahme.

Daher lässt sich auch leicht nachvollziehen, dass die MS-Forschung in den letzten Jahren einen enormen Zuwachs an experimentellen und klinischen Studien bezüglich einer neuroprotektiven Behandlungsoption zu verzeichnen hat. Allein in diesem Jahr (2009) können 
schon 129 klinische Studien zur Erprobung neuer oder zur Modulation bisheriger MS-Medikamente notiert werden. Darunter zielen circa $60 \%$ der Studien auf eine neuroprotektive Wirkung ab (www.nationalmssociety.org). Im Gegensatz zur Anzahl der Studien sind die Ergebnisse bisher eher enttäuschend. Allerdings darf nicht vergessen werden, dass sowohl Ätiologie als auch Pathogenese der MS zu großen Teilen noch unbekannt sind und damit die Forschung vorerst nicht ganz zielgerichtet erfolgen kann. Möglich ist es, dass sich auf der Suche nach neuen Therapiestrategien auch zusätzliche Fenster zum Verständnis der Immunpathogenese der MS öffnen werden.

Die derweil untersuchten anti-inflammatorischen und potentiell neuroprotektiven Ansätze zielen in vielerlei Richtungen. So wird versucht in den Zyklus der Antigenpräsentation und T-Zell-Aktivierung sowie auch in die B-Zell-Aktivierung und die Antikörperbildung einzugreifen. Die Untersuchung, Entzündungszellen an Chemotaxis, Adhäsion und Migration in das ZNS zu hindern, erwies sich teilweise als erfolgreich. Der monoklonale Antikörper Natalizumab, welcher aktivierte Lymphozyten daran hindert, die BHS zu überwinden, ist bereits in das Stufenschema der international anerkannten MS-Therapie-Leitlinien als antiinflammatorisch wirkende Substanz aufgenommen worden (Polman et al. 2006; Miller et al. 2007). Allerdings fehlt auch bei dieser Substanz die erhoffte neuroprotektive Komponente.

Auch dem Immunsystem nicht zugehörige Moleküle sind Ziel experimenteller Studien. Ein kleiner Erfolg zeigte eine im EAE-Modell durchgeführte Behandlung mit Epo (Sättler et al. 2004). Dabei konnte ein deutlich verbessertes Überleben der RGZ beobachtet werden. Allerdings hatte die kontinuierliche Epo-Therapie keinen positiven Einfluss auf den induzierten Entzündungsprozess, sodass eine alleinige Gabe von Epo nicht als ideale Behandlungsstrategie gelten kann. Wird Epo zusammen mit einer entzündungshemmenden Substanz wie beispielsweise Methylprednisolon verabreicht, wird ein sowohl antiinflammatorischer, als auch neuroprotektiver Effekt beschrieben (Diem et al. 2005).

In Bezug auf weitere Therapieoptionen, die gleichzeitig sowohl die Entzündung als auch die Neurodegeneration beeinflussen, konnte durch Hemmung des Moleküls Nogo-A durch einen monoklonalen Antikörper eine derartige Wirkung nachgewiesen werden (Karnezis et al. 2004). Es bleibt abzuwarten, ob diese Behandlung auch in klinischen Studien Erfolge zeigen wird. 


\subsection{DIE ANTIKÖRPER-GETRIGGERTE ANTAGONISIERUNG VON RGMA- EINE POTENTE, INNOVATIVE BEHANDLUNGSSTRATEGIE DER MS?}

RGMa ist ein Glykoprotein der Familie der Lenkmoleküle, welches bisher hauptsächlich in Verbindung mit dessen repulsivem Effekt im Milieu der glialen Narbe Erwähnung findet (Stahl et al. 1990; Müller et al. 1990; Matsunaga et al. 2004). Unter den beiden ZNSspezifischen RGM-Subtypen (RMGa und RGMb) ist RGMa das genauer charakterisierte Molekül und wird deswegen in Studien bevorzugt untersucht. In dieser Arbeit wurde ein Antikörper gegen RGMa erstmalig im entzündlich degenerativen EAE-Modell auf eine potentiell anti-inflammatorische sowie neuroprotektive Wirkung untersucht.

Die in dieser Arbeit durchgeführten Expressionsanalysen zeigen eine Lokalisation von RGMa in den Neuronen des ZNS von Ratten mit und ohne EAE. Beim Vergleich mit gesunden Kontrollen kann in der MOG-induzierten EAE ein vermehrtes Vorkommen von RGMaMolekülen in den entzündlichen Arealen des Rückenmarks beobachtet werden, nicht jedoch in Arealen ohne entzündliche Infiltration. Noch unpublizierte Studien unserer Arbeitsgruppe zeigen zudem eine vermehrte Expression von RGMa im Liquor von MS-Patienten. In Untersuchungen an Lewis Ratten mit Rückenmarksverletzungen wurde ein vermehrtes Auftreten von RGMa in Oligodendrozyten, myelinisierten Strukturen und Neuronen innerhalb des Läsionsbereichs beobachtet (Schwab et al. 2005a). Die Arbeitsgruppe von Schwab et al. erforschte des Weiteren die Expression von RGMa an post-mortem-Hirnschnitten von Patienten, die aufgrund von ischämischen oder traumatischen Ereignissen verstarben. Hierbei akkumulierte RGMa in den läsionierten und periläsionierten Arealen. Das in dieser Arbeit beobachtete vermehrte Auftreten von RGMa in EAE-Läsionen- in Übereinstimmung mit Liquoruntersuchungen von MS-Patienten- deutet daraufhin, dass dieses Protein an der Interaktion von Entzündung und Neurodegeneration dieser Erkrankungen beteiligt sein könnte. Allerdings lässt sich dabei eine vermehrte Expression von RGMa nicht direkt belegen, da eine Akkumulation des Moleküls beispielsweise durch einen verringerten Abbau nicht ausgeschlossen werden kann. Experimente, in denen in situ die RGMa-mRNAExpression untersucht wird, könnten darüber Aufschluss geben.

Da RGMa ein potenter Myelin-assoziierter Inhibitor des Neuritenwachstums ist, hat eine Antagonisierung dieses Moleküls durch einen neutralisierenden Antikörper einen positiven Einfluss auf die Axonregeneration. Eine Studie von Hata et al. (2006) untersuchte die Wirkung von $\alpha$-RGMa im Vergleich zu dem als Placebo wirkenden Immunglobulin G (IgG) im Rattenmodell. Dazu wurde der Antikörper nach Durchführung einer Hemisektion des 
thorakalen Rückenmarks per osmotischer Minipumpe intrathekal appliziert. Es konnte ein vermehrtes Auftreten von axonalen Ausprossungen und, möglicherweise damit verbunden, eine Besserung der Lokomotorik beobachtet werden.

In Bezug auf das MOG-EAE Modell ist eine Axonregeneration wesentlich schwieriger zu evaluieren, da hierbei die inflammatorische Komponente zu unterschiedlichen Läsionen bei jedem einzelnen Tier führt. Zudem sind die lädierten Areale im Gegensatz zu Modellen mit Hemisektion diffus im ZNS zerstreut, was die Detektion regenerierender Axone durch spezifische immunhistochemische Färbungen erschwert und oft sogar unmöglich macht. Allerdings besteht der Vorteil einer solchen Antagonisierung durch einen Antikörper gegen RGMa im MOG-induzierten Optikusneuritismodell darin, dass sowohl die neuroprotektiven als auch die anti-inflammatorischen Effekte quantitativ untersucht werden können. Da auch schon für Antikörper gegen das Lenkmolekül Nogo-A im EAE-Modell eine gleichzeitige neuroprotektive und anti-inflammatorische Wirkung beobachtet werden konnte (Karnezis et al. 2004), war die Hypothese entstanden, dass durch eine Antagonisierung gegen RGMa im EAE-Modell ähnliche positive Effekte zu erreichen sein könnten.

Das vermehrte Auftreten von RGMa-Molekülen in den entzündlichen ZNS-Läsionen des MOG-induzierten EAE-Modells lässt eine Beteiligung von RGMa an den entzündlichen und neurodegenerativen Prozessen dieser Erkrankung vermuten. Allerdings kann über die funktionelle Wichtigkeit von RGMa im Rahmen dieser Bedingungen nur spekuliert werden. Vielleicht ist RGMa nur indirekt an den Geschehnissen der Inflammation und der Neurodegeneration beteiligt. Dies würde die fehlende Wirkung des im Rahmen dieser Arbeit verwendeten Antikörpers gegen RGMa erklären.

Möglich wäre auch, dass die Ausschaltung von nur einem an der Initiierung von Inflammation und Neurodegeneration beteiligten Molekül- hier in dieser Arbeit RGMakeinen oder nur einen mäßigen neuroprotektiven and anti-inflammatorischen Effekt hervorruft, jedoch eine Kombinationsbehandlung gegen weitere Lenkmoleküle wie zum Beispiel Nogo (Karnezis et al. 2004) die erwünschte Wirkung bringen könnte.

Die Antagonisierung von RGMa als gleichzeitige Behandlungsmöglichkeit der autoimmunen Entzündung und der Neurodegeneration im Tiermodell der MS erbrachte keine Erfolge, wobei über die Ursache der fehlenden Wirkung an dieser Stelle nur spekuliert werden kann. Sowohl RGMa als Molekül, als auch die Mechanismen seiner möglichen Beteiligung an der Interaktion von autoimmuner Entzündung und Neurodegeneration bei EAE und MS müssen genauer entschlüsselt werden, um eine endgültige Antwort auf die fehlende Wirkung finden 
zu können. Zukünftige Studien werden zeigen, ob die Erforschung weiterer MAbs, die spezifisch auf das Zusammenspiel von Inflammation und Neurodegeneration abzielen, therapeutische Erfolge bringen wird und damit die Entwicklung eines Behandlungskonzeptes, welches auf beide Aspekte dieser Erkrankung abzielt, möglich macht. 


\section{ZUSAMMENFASSUNG}

Multiple Sklerose ist eine entzündlich demyelinisierende Erkrankung des ZNS. Das histopathologische Bild zeigt einen kontinuierlichen Zerfall der Myelinscheiden, bedingt durch entzündliche Läsionen. Zusätzlich tritt eine Destruktion axonaler und neuronaler Strukturen auf, die die wichtigste Ursache der dauerhaft bestehenden Behinderungen der Patientinnen und Patienten ist. Sämtliche etablierte Behandlungskonzepte zielen auf die inflammatorische Komponente der Erkrankung ab. Da auch moderne anti-inflammatorische Therapiekonzepte die langsam fortschreitende Zunahme persistierender Behinderungen häufig nicht aufhalten können, kommt der Entwicklung neuroprotektiver Therapieansätze zur Begrenzung des irreversiblen neuronalen Schadens eine entscheidende Bedeutung zu.

In dieser Arbeit wurden in einem Rattenmodell der Experimentellen Autoimmunen Enzephalomyelitis (EAE), dem am häufigsten eingesetzten Tiermodell der MS, die Wirkungen von monoklonalen Antikörpern gegen das „Repulsive Guidance Molecule a“ (RGMa) untersucht. RGMa ist ein Molekül aus der Familie der Lenkmoleküle und wurde zuerst in seiner Funktion bei der neuronalen Entwicklung des visuellen Systems beschrieben. Darüber hinaus ist eine die Axonregeneration fördernde Wirkung in einem spinalen Traumamodell beobachtet worden. Im Rahmen der hier vorgelegten Arbeit wurden zunächst Expressionsanalysen von RGMa durchgeführt, welche das Vorkommen dieses Moleküls in neuronalen Strukturen des untersuchten Tiermodells bestätigten. Der Vergleich von Präparaten gesunder und EAE-Ratten deutete auf ein vermehrtes Vorkommen von RGMaMolekülen in den entzündlich demyelinisierten Arealen hin. Die Antikörperbehandlung wurde im Vergleich zu zwei verschiedenen Kontrollbehandlungen durchgeführt. Eine Tiergruppe erhielt PBS als Placebo, die andere Kontrollgruppe einen monoklonalen Antikörper gegen humanes RGMa. Bei Brown Norway Ratten mit autoimmuner Optikusneuritis, induziert durch Immunisierung mit Myelin-Oligodendrozyten-Glykoprotein, wurde mittels intraperitonealer Applikation von 1 oder 4 mg/kg Körpergewicht dosierten RGMa-Antikörper weder ein Effekt auf die entzündliche Infiltration in den Sehnerven, noch auf die Demyelinisierung, die axonale Degeneration oder den neuronalen Zelltod beobachtet. Die fehlende neuroprotektive und anti-inflammatorische Wirkung resultierte in ebenfalls unveränderten klinischen Funktionsdefiziten der Tiere, die in diesem Tiermodell vor allem durch die zusätzlich zur Optikusneuritis auftretenden spinalen Läsionen hervorgerufen werden. Die Ergebnisse dieser Arbeit unterstreichen die Notwendigkeit weiterer experimenteller und klinischer Studien, um die Interaktion von Entzündung und 
Neurodegeneration bei der MS weiter zu entschlüsseln und die Entwicklung einer gleichzeitig anti-inflammatorisch und neuroprotektiv wirksamen Monotherapie zu ermöglichen. 


\section{ANHANG: ABKÜRZUNGEN UND EINHEITEN}

$\alpha-$

$\beta$-APP

BHS

$\mathrm{BN}$

CTNF

EAE

EDSS

Epo

FCI

FG

HLA

Ig

IL

LBF

$\mathrm{MAb}$

MAG

MBP

MOBP

MOG

MRS

MRT

MS

PBS

PFA

PLP

PML

RGM

RGM

RGZ

RT

SCI

TBI
Antikörper

engl. $\beta$-amyloid precursor protein

Blut-Hirn-Schranke

engl. Brown Norway

ziliarer Nervenwachstumsfaktor

Experimentelle Autoimmune Enzephalomyelitis

engl. expanded disability status score

Erythropoetin

engl. focal cerebral ischemia

Fluorogold

humanes Leukozytenantigen

Immunglobulin

Interleukin

Luxol-Fast-Blue

monoklonaler Antikörper

Myelin-assoziiertes Glykoprotein

basisches Myelinprotein

Myelin-assoziiertes Oligodendrozyten-Basisprotein

Myelin-Oligodendrozyten-Glykoprotein

Magnet-Resonanz-Spektroskopie

Magnet-Resonanz-Tomographie

Multiple Sklerose

engl. phosphate buffered saline

Paraformaldehyd

Proteolipid-Protein

progressive multifokale Leukenzephalie

engl. repulsive guidance molecule

engl. repulsive guidance molecule a

retinale Ganglienzelle/-n

Raumtemperatur

engl. spinal cord injury

engl. traumatic brain injury 
TNF

UV

VLA

ZNS

${ }^{\circ} \mathrm{C}$

$\mathrm{kDa}, \mathrm{Da}$

$\mathrm{kg}, \mathrm{g}, \mathrm{mg}, \mu \mathrm{g}$

h, min, sec

$1, \mathrm{ml}, \mu \mathrm{l}$

$\mathrm{M}, \mathrm{mM}, \mathrm{nM}, \mathrm{pM}$
Tumornekrosefaktor

Ultraviolett

engl. very late antigen

zentrales Nervensystem

Grad Celsius

Kilodalton, Dalton

Kilogramm, Gramm, Milligramm, Mikrogramm

Stunde, Minute, Sekunde

Liter, Milliliter, Mikroliter

Molar, Millimolar, Nanomolar, Picomolar 


\section{LITERATURVERZEICHNIS}

Aloisi F, Columba-Cabezas S, Franciotta D, Rosicarelli B, Magliozzi R, Reynolds R, Ambrosini E, Coccia E, Salvetti M, Serafini B (2008): Lymphoid chemokines in chronic neuroinflammation. J Neuroimmunol $\underline{198}$, 378-387

Amor S, Groome N, Linington C, Morris MM, Dornmair K, Gardinier MV, Matthieu JM, Baker D (1994): Identification of epitopes of myelin oligodendrocyte glycoprotein for the induction of experimental allergic encephalomyelitis in SJL and Biozzi $\mathrm{AB} / \mathrm{H}$ mice. J Immunol 153, 4349-4356

Andersson PB, Goodkin DE (1996): Current pharmacologic treatment of multiple sclerosis symptoms. West J Med $\underline{165}, 1353-1364$

Ascherio A, Munger KL, Lennette ET, Spiegelman D, Hernan MA, Olek MJ, Hankinson SE, Hunter DJ (2001): Epstein-Barr virus antibodies and risk of multiple sclerosis: a prospective study. JAMA $\underline{286}, 3083-3088$

Barnes D, McDonald WI (1992): The ocular manifestations of multiple sclerosis. 2. Abnormalities of eye movements. J Neurol Neurosurg Psychiatry 55, 863-868

Bayas A, Gold R (2003): Lessons from 10 years of interferon beta-1b (Betaferon®/Betaseron ${ }^{\circledR}$ ) treatment. J Neurol 250 Suppl 14, 3-8

Ben-Nun A, Wekerle H, Cohen IR (1981): Vaccination against autoimmune encephalomyelitis with T-lymphocite line cells reactive against myelin basic protein. Nature $\underline{292}, 60-61$

Bielekova B, Catalfamo M, Reichert-Scrivner S, Packer A, Cerna M, Waldmann TA, McFarland H, Henkart PA, Martin R (2006): Regulatory CD56 (bright) natural killer cells mediate immunomodulatory effects of IL-2R $\alpha$-targeted therapy (daclizumab) in multiple sclerosis. Proc Natl Acad Sci U S A 103, 5941-5946 
Bitsch A, Brück W (2002): Differentiation of multiple sclerosis subtypes: implications for treatment. CNS drugs $\underline{16}, 405-418$

Bjartmar C, Trapp BD (2001): Axonal and neuronal degeneration in multiple sclerosis: mechanisms and functional consequences. Curr Opin Neurol 14, 271-278

Bregman BS, Kunkel-Bagden E, Schnell L, Dai HN, Gao D, Schwab ME (1995): Recovery from spinal cord injury mediated by antibodies to neurite growth inhibitors. Nature $\underline{378}, 498-$ 501

Brück W, Stadelmann C (2003): Inflammation and degeneration in multiple sclerosis. Neurol Sci 24 Suppl 5, S265-267

Brück W, Stadelmann C (2005): The spectrum of multiple sclerosis: new lessons from pathology. Curr Opin Neurol 18, 221-224

Brück W, Porada P, Poser S, Rieckmann P, Hanefeld F, Kretzschmar HA, Lassmann H (1995): Monocyte/macrophage differentiation in early multiple sclerosis lesions. Ann Neurol $\underline{38}, 788-796$

Brück W, Kuhlmann T, Stadelmann C (2003): Remyelination in multiple sclerosis. J Neurol Sci 206, 181-185

Burgoon MP, Williamson RA, Owens GP, Ghausi O, Bastidas RB, Burton DR, Gilden DH (1999): Cloning the antibody response in humans with inflammatory CNS disease: isolation of measles virus-specific antibodies from phage display libraries of a subacute sclerosing panencephalitis brain. J Neuroimmunol $\underline{94}$, 204-211

Cambi F, Lees MB, Williams RM, Macklin WB (1983): Chronic experimental allergic encephalomyelitis produced by bovine proteolipid apoprotein: immunological studies in rabbits. Ann Neurol 13, 303-308

Cannella B, Raine CS (1995): The adhesion molecule and cytokine profile of multiple sclerosis lesions. Ann Neurol 37, 424-435 
Charcot JM (1868): Histologie de sclérose en plaques. Gaz Hop (Paris) 411, 554-566

Chen MS, Huber AB, van der Haar ME, Frank M, Schnell L, Spillmann AA, Christ F, Schwab ME (2000): Nogo-A is a myelin-associated neurite outgrowth inhibitor and an antigen for monoclonal antibody IN-1. Nature $\underline{403}, 434-439$

Coles AJ, Cox A, Le Page E, Jones J, Trip SA, Deans J, Seaman S, Miller DH, Hale G, Waldmann $\mathrm{H}$ et al. (2006): The window of therapeutic opportunity in multiple sclerosis: evidence from monoclonal antibody therapy. J Neurol 253, 98-108

Cross AH, Stark JL, Lauber J, Ramsbottom MJ, Lyons JA (2006): Rituximab reduces B cells and $\mathrm{T}$ cells in cerebrospinal fluid of multiple sclerosis patients. J Neuroimmunol $\underline{180}, 63-70$

Davie CA, Barker GJ, Webb S, Tofts PS, Thompson AJ, Harding AE, McDonald WI, Miller DH (1995): Persistent functional deficit in multiple sclerosis and autosomal dominant cerebellar ataxia is associated with axon loss. Brain $\underline{118}, 1583-1592$

De Stefano N, Matthews PM, Fu L, Narayanan S, Stanley J, Francis GS, Antel JP, Arnold DL (1998): Axonal damage correlates with disability in patients with relapsing-remitting multiple sclerosis. Results of a longitudinal magnetic resonance spectroscopy study. Brain $\underline{121}, 1469$ 1477

De Stefano N, Filippi M, Miller D, Pouwels PJ, Rovira A, Gass A, Enzinger C, Matthews PM, Arnold DL (2007): Guidelines for using proton MR spectroscopy in multicenter clinical MS studies. Neurology $\underline{69}, 1942-1952$

De Vries M, Cooper HM (2008): Emerging roles for neogenin and its ligands in CNS development. J Neurochem $\underline{106}, 1483-1492$

Diem R, Hobom M, Maier K, Weissert R, Storch MK, Meyer R, Bähr M (2003): Methylprednisolone increases neuronal apoptosis during autoimmune CNS inflammation by inhibition of an endogenous neuroprotective pathway. J Neurosci $\underline{23}, 6993-7000$ 
Diem R, Sättler MB, Merkler D, Demmer I, Maier K, Stadelmann C, Ehrenreich H, Bähr M (2005): Combined therapy with methylprednisolone and erythropoietin in a model of multiple sclerosis. Brain $\underline{128}, 375-385$

Drescher U (1997): The Eph family in the patterning of neural development. Curr Biol 7, 799807

Dundar Y, Bagust A, Hounsome J, McLeod C, Boland A, Davis H, Walley T, Dickson R (2009): Rituximab for the first-line treatment of stage III/IV follicular non-Hodgkin's lymphoma. Health Technol Assess $\underline{13}$ Suppl 1, 23-28

Ebers GC, Bulman DE, Sadovnick AD, Paty DW, Warren S, Hader W, Murray TJ, Seland TP, Duquette P, Grey T (1986): A population-based study of multiple sclerosis in twins. N Engl J Med $\underline{315}$, 1638-1642

Fawcett JW, Asher RA (1999): The glial scar and central nervous system repair. Brain Res Bull 쏘, 377-391

Ferguson B, Matyszak MK, Esiri MM, Perry VH (1997): Axonal damage in acute multiple sclerosis lesions. Brain 120, 393-399

Fisher E, Rudick RA, Cutter G, Baier M, Miller D (2000): Relationship between brain atrophy and disability: an 8-year follow-up study of multiple sclerosis patients. Mult Scler $\underline{6}$, 373-377

Fitch MT, Doller C, Combs CK, Landreth GE, Silver J (1999): Cellular and molecular mechanisms of glial scarring and progressive cavitation: in vivo and in vitro analysis of inflammation-induced secondary injury after CNS trauma. J Neurosci $\underline{19}, 8182-8198$

Flachenecker P, Zettl UK, Götze U, Haas J, Schimrigk S, Elias W, Pette M, Eulitz M, Hennig M, Bertram J et al. (2005): MS registry in Germany - design and first results of the pilot phase. Nervenarzt $\underline{76}, 967-975$ 
Freund P, Schmidlin E, Wannier T, Bloch J, Mir A, Schwab ME, Rouiller EM (2006): Nogo-A-specific antibody treatment enhances sprouting and functional recovery after cervical lesion in adult primates. Nat Med $\underline{12}, 790-792$

Friese MA, Montalban X, Willcox N, Bell JI, Martin R, Fugger L (2006): The value of animal models for drug development in multiple sclerosis. Brain $\underline{129}, 1940-1952$

Gale CR, Martyn CN (1995): Migrant studies in multiple sclerosis. Prog Neurobiol 47, 425448

Gold R, Linington C, Lassmann H (2006): Understanding pathogenesis and therapy of multiple sclerosis via animal models: 70 years of merits and culprits in experimental autoimmune encephalomyelitis research. Brain $\underline{129}$, 1953-1971

Gold R, Jawad A, Miller DH, Henderson DC, Fassas A, Fierz W, Hartung HP (2007): Expert opinion: guidelines for the use of natalizumab in multiple sclerosis patients previously treated with immunomodulating therapies. J Neuroimmunol $\underline{187}, 156-158$

Goodin DS, Frohman EM, Garmany GP Jr, Halper J, Likosky WH, Lublin FD, Silberberg DH, Stuart WH, van den Noort S (2002): Disease modifying therapies in multiple sclerosis: report of the Therapeutics and Technology Assessment Subcommittee of the American Academy of Neurology and the MS Council for Clinical Practice Guidelines. Neurology $\underline{71}$, 766-773

GrandPré T, Nakamura F, Vartanian T, Strittmatter SM (2000): Identification of the Nogo inhibitor of axon regeneration as a Reticulon protein. Nature $\underline{403}, 439-444$

Grimaud J, Barker GJ, Wang L, Lai M, MacManus DG, Webb SL, Thompson AJ, McDonald WI, Tofts PS, Miller DH (1999): Correlation of magnetic resonance imaging parameters with clinical disability in multiple sclerosis: a preliminary study. J Neurol $\underline{246}, 961-967$

Guth L, Barrett CP, Donati EJ, Anderson FD, Smith MV, Lifson M (1985): Essentiality of a specific cellular terrain for growth of axons into a spinal cord lesion. Exp Neurol $\underline{88}, 1-12$ 
Haines JL, Ter-Minassian M, Bazyk A, Gusella JF, Kim DJ, Terwedow H, Pericak-Vance MA, Rimmler JB, Haynes CS, Roses AD et al. (1996): A complete genomic screen for multiple sclerosis underscores a role for the major histocompatability complex. The Multiple Sclerosis Genetics Group. Nat Genet $\underline{13}$, 469-471

Hata K, Fujitani M, Yasuda Y, Doya H, Saito T, Yamagishi S, Mueller BK, Yamashita T (2006): RGMa inhibition promotes axonal growth and recovery after spinal cord injury. J Cell Biol $\underline{173}, 47-88$

Karnezis T, Mandemakers W, McQualter JL, Zheng B, Ho PP, Jordan KA, Murray BM, Barres B, Tessier-Lavigne M, Bernard CC (2004): The neurite outgrowth inhibitor Nogo A is involved in autoimmune-mediated demyelination. Nat Neurosci $\underline{7}, 736-744$

Kaye JF, Kerlero de Rosbo N, Mendel I, Flechter S, Hoffman M, Yust I, Ben-Nun A (2000): Central nervous system-specific myelin oligodendrocytic basic protein (MOBP) is encephalitogenic and a potential target antigen in multiple sclerosis (MS). J Neuroimmunol $\underline{102}, 189-198$

Keegan M et al. (2005): Relation between humoral pathological changes in multiple sclerosis and response to therapeutic plasma exchange. Lancet $\underline{366}, 579-582$

Kies MW, Thompson EB, Alvord EC Jr. (1965): The relationship of myelin proteins to experimental allergic encephalomyelitis. Ann N Y Acad Sci 122, 148-160

Kleinschnitz C, Meuth SG, Stüve O, Kieseier B, Wiendl H (2007): Multiple sclerosis therapy: an update on recently finished trials. J Neurol 254, 1473-1490

Kohler G, Milstein C (1975): Continuous cultures of fused cells secreting antibody of predefined specificity. Nature $\underline{256}, 495-497$

Kornek B, Lassmann H (2003): Neuropathology of multiple sclerosis - new concepts. Brain Res Bull 61, 321-326 
Kornek B, Storch MK, Weissert R, Wallstroem E, Stefferl A, Olsson T, Linington C, Schmidbauer M, Lassmann H (2000): Multiple sclerosis and chronic autoimmune encephalomyelitis - a comparative quantitative study of axonal injury in active, inactive, and remyelinated lesions. Am J Pathol 157, 267-276

Kuhlmann T, Lingfeld G, Bitsch A, Schuchardt J, Brück W (2002): Acute axonal damage in multiple sclerosis is most extensive in early disease stages and decreases over time. Brain $\underline{125}, 2202-2212$

Kurtzke JF (1980): Epidemiologic contributions to multiple sclerosis: an overview. Neurology $\underline{30}, 61$

Kurtzke JF: Epidemiology of MS; in: Handbook of clinical neurology; hrsg. v. Vinken PJ, Bruyn GW, Klawans HL, Koetsier JC; Elsevier Science, Amsterdam/New York 1985, 259287

Kutzelnigg A, Lucchinetti CF, Stadelmann C, Brück W, Rauschka H, Bergmann M, Schmidbauer M, Parisi JE, Lassmann H (2005): Cortical demyelination and diffuse white matter injury in multiple sclerosis. Brain $\underline{128}, 2705-2712$

Kyoto A, Hata K, Yamashita T (2007): Synapse formation of the cortico-spinal axons is enhanced by RGMa inhibition after spinal cord injury. Brain Res $\underline{1186}, 74-86$

Lassmann H, Brück W, Lucchinetti C (2001): Heterogeneity of multiple sclerosis pathogenesis: implications for diagnosis and therapy. Trends Mol Med , 115-121

Le Gros Clark WE (1943): The problem of neuronal regeneration in the central nervous system: II. The insertion of peripheral nerve stumps into the brain. J Anat $\underline{77}$, 251-259

Li Y, Raisman G (1995): Sprouts from cut corticospinal axons persist in the presence of astrocytic scarring in long-term lesions of the adult rat spinal cord. Exp Neurol 134, 102-111 
Linington C, Berger T, Perry L, Weerth S, Hinze-Selch D, Zhang Y, Lu HC, Lassmann H, Wekerle H (1993): T cells specific for the myelin oligodendrocyte glycoprotein mediate an unusual autoimmune inflammatory response in the central nervous system. Eur J Immunol $\underline{23}$, $1364-1372$

Liu CN, Chamber WW (1958): Intraspinal sprouting of dorsal root axons; development of new collaterals and preterminals following partial denervation of the spinal cord in the cat. AMA Arch Neurol Psychiatry $\underline{79}, 46-61$

Lublin FD, Reingold SC (1996): Defining the clinical course of multiple sclerosis: results of an international survey. National Multiple Sclerosis Society (USA) Advisory Committee on Clinical Trials of New Agents in Multiple Sclerosis. Neurology 46, 907-911

Madsen LS, Andersson EC, Jansson L, Krogsgaard M, Andersen CB, Engberg J, Strominger JL, Svejgaard A, Hjorth JP, Holmdahl R et al. (1999): A humanized model for multiple sclerosis using HLA-DR2 and a human T-cell receptor. Nat Genet 23, 343-347

Maier K, Rau CR, Storch MK, Sättler MB, Demmer I, Weissert R, Taheri N, Kuhnert AV, Bähr M, Diem R (2004): Ciliary neurotrophic factor protects retinal ganglion cells from secondary cell death during acute autoimmune optic neuritis in rats. Brain Pathol $\underline{14}, 378-387$

Maier K, Kuhnert AV, Taheri N, Sättler MB, Storch MK, Williams SK, Bähr M, Diem R (2006): Effects of glatiramer acetate and interferon-beta on neurodegeneration in a model of multiple sclerosis: a comparative study. Am J Pathol $\underline{169}$, 1353-1364

Matsunaga E, Chédotal A (2004): Repulsive guidance molecule/neogenin: a novel ligandreceptor system playing multiple roles in. Dev Growth Differ $\underline{46}$, 481-486

Matsunaga E, Tauszig-Delamasure S, Monnier PP, Mueller BK, Strittmatter SM, Mehlen P, Chédotal A (2004): RGM and its receptor neogenin regulate neuronal survival. Nat Cell Biol $\underline{6}, 749-755$

Matsunaga E, Nakamura H, Chédotal A (2006): Repulsive guidance molecule plays multiple roles in neuronal differentiation and axon guidance. J Neurosci 26, 6082-6088 
Matthews PM, De Stefano N, Narayanan S, Francis GS, Wolinsky JS, Antel JP, Arnold DL (1998): Putting magnetic resonance spectroscopy studies in context: axonal damage and disability in multiple sclerosis. Semin Neurol $\underline{18}, 327-336$

Melcangi RC, Cavarretta I, Magnaghi V, Ciusani E, Salmaggi A (2000): Corticosteroids protect oligodendrocytes from cytokine-induced cell death. Neuroreport 11, 3969-3972

Merkler D, Metz GA, Raineteau O, Dietz V, Schwab ME, Fouad K (2001): Locomotor recovery in spinal cord-injured rats treated with an antibody neutralizing the myelinassociated neurite growth inhibitor Nogo-A. J Neurosci 21, 3665-3673

Meyer R, Weissert R, Diem R, Storch MK, de Graaf KL, Kramer B, Bähr M (2001): Acute neuronal apoptosis in a rat model of multiple sclerosis. J Neurosci $\underline{21}, 6214-6220$

Miller DH et al. (2007): MRI outcomes in a placebo-controlled trial of natalizumab in relapsing MS. Neurology $\underline{68}, 1390-1401$

Misgeld T, Kerschensteiner M (2006): In vivo imaging of the diseased nervous system. Nat Rev Neurosci $\underline{7}, 449-463$

Monnier PP, Sierra A, Macchi P, Deitinghoff L, Andersen JS, Mann M, Flad M, Hornberger MR, Stahl B, Bonhoeffer F et al. (2002): RGM is a repulsive guidance molecule for retinal axons. Nature $\underline{419}, 392-395$

Müller B, Stahl B, Bonhoeffer F (1990): In vitro experiments on axonal guidance and growthcone collapse. J Exp Biol 153, 29-46

Niederkofler V, Salie R, Sigrist M, Arber S (2004): Repulsive guidance molecule (RGM) gene function is required for neural tube closure but not retinal topography in the mouse visual system. J Neurosci $\underline{24}$, 808-818

Noseworthy J, Paty D, Wonnacott T, Feasby T, Ebers G (1983): Multiple sclerosis after age 50. Neurology $\underline{33}, 1537-1544$ 
Oksenberg JR, Barcellos LF (2000): The complex genetic aetiology of multiple sclerosis. J Neurovirol $\underline{6}$ Suppl 2, 10-14

Oldekamp J, Krämer N, Alvarez-Bolado G, Skutella T (2004): Expression pattern of the repulsive guidance molecules RGM A, B and C during mouse development. Gene Expr Patterns $\underline{4}, 283-288$

Paolillo A, Pozzilli C, Gasperini C, Giugni E, Mainero C, Giuliani S, Tomassini V, Millefiorini E, Bastianello S (2000): Brain atrophy in relapsing-remitting multiple sclerosis: relationship with'black holes', disease duration and clinical disability. J Neurol Sci 174, 85-91

Petereit HF, Moeller-Hartmann W, Reske D, Rubbert A (2008): Rituximab in a patient with multiple sclerosis--effect on B cells, plasma cells and intrathecal IgG synthesis. Acta Neurol Scand $\underline{117}, 399-403$

Peterson JW, Bo L, Mork S, Chang A, Trapp BD (2001): Transected neurites, apoptotic neurons, and reduced inflammation in cortical multiple sclerosis lesions. Ann Neurol 50, 389400

Poeck K, Hacke W: Neurologie, 10. Auflage; Springer-Verlag, Berlin 1998

Polman CH et al. (2006): A randomized, placebo-controlled trial of natalizumab for relapsing multiple sclerosis. N Engl J Med 354, 899-910

Prinjha R, Moore SE, Vinson M, Blake S, Morrow R, Christie G, Michalovich D, Simmons DL, Walsh FS (2000): Neurobiology: Inhibitor of neurite outgrowth in humans. Nature $\underline{403}$, 383-384

Putzki N, Yaldizli O, Maurer M, Cursiefen S, Kuckert S, Klawe C, Maschke M, Tettenborn B, Limmroth V (2009): Efficacy of natalizumab in second line therapy of relapsing-remitting multiple sclerosis: results from a multi-center study in German speaking countries. (Eur J Neurol, im Druck) 
Queen C, Schneider WP, Selick HE, Payne PW, Landolfi NF, Duncan JF, Avdalovic NM, Levitt M, Junghans RP, Waldmann TA (1989): A humanized antibody that binds to the interleukin 2 receptor. Proc Natl Acad Sci U S A $\underline{86}$, 10029-10033

Rainiene T, Dobrovolskiene R, Dainys B, Kucinskis G, Zelvys A (2007): Clinical effect of induction therapy with monoclonal antibodies after deceased-donor kidney transplantation (an experience from Vilnius Center). Medicina (Kaunas) 43 Suppl 1, 109-113

Rajagopalan S, Deitinghoff L, Davis D, Conrad S, Skutella T, Chedotal A, Mueller BK, Strittmatter SM (2004): Neogenin mediates the action of repulsive guidance molecule. Nat Cell Biol $\underline{6}, 756-762$

Rieckmann P (2006): Escalating immunomodulatory therapy of multiple sclerosis. Update (September 2006). Nervenarzt $\underline{77}, 1506-1518$

Rieckmann P (2009): Concepts of induction and escalation therapy in multiple sclerosis. J Neurol Sci 277 Suppl 1, S42-45

Rivers TM, Schwentker FF (1935): Encephalomyelitis accompanied by myelin destruction experimentally produced in monkeys. J Exp Med $\underline{61}$, 689-702

Rose JW, Foley JF, Carlson NG (2009): Monoclonal antibody treatments for multiple sclerosis. Curr Treat Options Neurol 11, 211-220

Ruggieri M, Polizzi A, Pavone L, Grimaldi LM (1999): Multiple sclerosis in children under 6 years of age. Neurology $\underline{53}, 478-484$

Sättler MB, Merkler D, Maier K, Stadelmann C, Ehrenreich H, Bähr M, Diem R (2004): Neuroprotective effects and intracellular signaling pathways of erythropoietin in a rat model of multiple sclerosis. Cell Death Differ 11 Suppl 2, 181-192

Sättler MB, Demmer I, Williams SK, Maier K, Merkler D, Gadjanski I, Stadelmann C, Bähr M, Diem R (2006): Effects of interferon-beta-1a on neuronal survival under autoimmune inflammatory conditions. Exp Neurol 201, 172-181 
Sättler MB, Togni M, Gadjanski I, Sühs KW, Meyer N, Bähr M, Diem R (2008a): Strainspecific susceptibility for neurodegeneration in a rat model of autoimmune optic neuritis. $\mathbf{J}$ Neuroimmunol $\underline{193}, 77-86$

Sättler MB, Williams SK, Neusch C, Otto M, Pehlke JR, Bähr M, Diem R (2008b): Flupirtine as neuroprotective add-on therapy in autoimmune optic neuritis. Am J Pathol $\underline{173}$, 1496-1507

Sawcer S, Maranian M, Setakis E, Curwen V, Akesson E, Hensiek A, Coraddu F, Roxburgh R, Sawcer D, Gray J et al. (2002): A whole genome screen for linkage disequilibrium in multiple sclerosis confirms disease associations with regions previously linked to susceptibility. Brain $\underline{125}, 1337-1347$

Schmidtmer J, Engelkamp D (2004): Isolation and expression pattern of three mouse homologues of chick Rgm. Gene Expr Patterns $\underline{4}$, 105-110

Schumacher GA (1974): Critique of experimental trials of therapy in multiple sclerosis. Neurology 24, 1010-1004

Schwab JM, Conrad S, Monnier PP, Julien S, Mueller BK, Schluesener HJ (2005a): Spinal cord injury-induced lesional expression of the repulsive guidance molecule (RGM). Eur J Neurosci 21, 1569-1576

Schwab JM, Monnier PP, Schluesener HJ, Conrad S, Beschorner R, Chen L, Meyermann R, Mueller BK (2005b): Central nervous system injury-induced repulsive guidance molecule expression in the adult human brain. Arch Neurol $\underline{62}, 1561-1568$

Silver J, Miller JH (2004): Regeneration beyond the glial scar. Nat Rev Neurosci $\underline{5}$, 146-156

Simmons DL (2005): Anti-adhesion therapies. Curr Opin Pharmacol 5, 398-404

Sobel RA, van der Veen RC, Lees MB (1986): The immunopathology of chronic experimental allergic encephalomyelitis induced in rabbits with bovine proteolipid protein. $\mathbf{J}$ Immunol 136, 157-163 
Soldan SS et al. (1997): Association of human herpes virus 6 (HHV-6) with multiple sclerosis: increased IgM response to HHV-6 early antigen and detection of serum HHV-6 DNA. Nat Med $\underline{3}, 1394-1397$

Stahl B, Müller B, von Boxberg Y, Cox EC, Bonhoeffer F (1990): Biochemical characterization of a putative axonal guidance molecule of the chick visual system. Neuron $\underline{5}$, $735-743$

Steinman L, Zamvil SS (2006): How to successfully apply animal studies in experimental allergic encephalomyelitis to research on multiple sclerosis. Ann Neurol $\underline{60}, 12-21$

Stoll G, Müller HW (1999): Nerve injury, axonal degeneration and neural regeneration: basic insights. Brain Pathol $\underline{9}, 313-325$

Storch MK, Piddlesden S, Haltia M, Iivanainen M, Morgan P, Lassmann H (1998a): Multiple sclerosis: in situ evidence for antibody- and complement-mediated demyelination. Ann Neurol $\underline{43}, 465-471$

Storch MK, Stefferl A, Brehm U, Weissert R, Wallstrom E, Kerschensteiner M, Olsson T, Linington C, Lassmann H (1998b): Autoimmunity to myelin oligodendrocyte glycoprotein in rats mimics the spectrum of multiple sclerosis pathology. Brain Pathol $\underline{8}, 681-694$

Storch MK, Bauer J, Linington C, Olsson T, Weissert R, Lassmann H (2006): Cortical demyelination can be modeled in specific rat models of autoimmune encephalomyelitis and is major histocompatability complex (MHC) haplotype-related. J Neuropathol Exp Neurol $\underline{65}$, $1137-1142$

Tassew NG, Charish J, Chestopalova L, Monnier PP (2009): Sustained in vivo inhibition of protein domains using single-chain $\mathrm{Fv}$ recombinant antibodies and its application to dissect RGMa activity on axonal outgrowth. J Neurosci $\underline{29}, 1126-1131$

Taylor L, Jones L, Tuszynski MH, Blesch A (2006): Neurotrophin-3 gradients established by lentiviral gene delivery promote short-distance axonal bridging beyond cellular grafts in the injured spinal cord. J Neurosci 26, 9713-9721 
Tom VJ, Steinmetz MP, Miller JH, Doller CM, Silver J (2004): Studies on the development and behavior of the dystrophic growth cone, the hallmark of regeneration, in an in vitro model of the glial scar and after spinal cord injury. J Neurosci 24, 6531-6539

Trapp BD, Peterson J, Ransohoff RM, Rudick R, Mörk S, Bö L (1998): Axonal transection in the lesions of multiple sclerosis. N Engl J Med 338, 278-285

Wahl S, Barth H, Ciossek T, Aktories K, Mueller BK (2000): Ephrin-A5 induces collapse of growth cones by activating Rho and Rho kinase. J Cell Biol 149, 263-270

Waldner H, Whitters MJ, Sobel RA, Collins M, Kuchroo VK (2000): Fulminant spontaneous autoimmunity of the central nervous system in mice transgenic for the myelin proteolipid protein-specific T cell receptor. Proc Natl Acad Sci U S A 97, 3412-3417

Warnke C, Kieseier BC, Zettl U, Hartung HP (2009): Possibilities and risks of the monoclonal antibody alemtuzumab as a new treatment option for multiple sclerosis. Nervenarzt $\underline{80}, 468-474$

Weerth S, Berger T, Lassmann H, Linington C (1999): Encephalitogenic and neuritogenic T cell responses to the myelin-associated glycoprotein (MAG) in the Lewis rat. $\mathrm{J}$ Neuroimmunol 95, 157-164

Wikstrom J, Poser S, Ritter G (1980): Optic neuritis as an initial symptom in multiple sclerosis. Acta Neurol Scand $\underline{61}, 178-185$

Wujek JR, Bjartmar C, Richer E, Ransohoff RM, Yu M, Tuohy VK, Trapp BD (2002): Axon loss in the spinal cord determines permanent neurological disability in an animal model of multiple sclerosis. J Neuropathol Exp Neurol $\underline{61}$, 23-32

Yamashita T, Mueller BK, Hata K (2007): Neogenin and repulsive guidance molecule signaling in the central nervous system. Curr Opin Neurobiol 17, 29-34 
Yednock TA, Cannon C, Fritz L C, Sanchez-Madrid F, Steinman L, Karin N (1992): Prevention of experimental autoimmune encephalomyelitis by antibodies against alpha 4 beta 1 integrin. Nature $\underline{356}, 63-66$

Zehntner SP, Brisebois M, Tran E, Owens T, Fournier S (2003): Constitutive expression of a costimulatory ligand on antigen-presenting cells in the nervous system drives demyelinating disease. FASEB J $\underline{17}, 1910-1912$ 


\section{DANKSAGUNG}

Herrn Prof. Dr. med. Mathias Bähr danke ich für die freundliche Unterstützung, Betreuung und Anregung zu dieser Arbeit.

Mein herzlichster Dank gilt Frau PD Dr. Muriel Sättler. Sowohl ihr Engagement und Motivationsgeist als auch ihre fachliche Kompetenz und ihr Interesse an meinen Fortschritten trugen maßgeblich zum Gelingen dieser Arbeit bei.

Dankbar bin ich Frau Dr. med. Katharina Maier für die hervorragende Zusammenarbeit, für viele lehrreiche Stunden im Labor und für ihre grenzenlose Hilfsbereitschaft.

Des Weiteren danke ich der gesamten Arbeitsgruppe für die motivierte und zugleich entspannende Atmosphäre im Labor. Bei Ina Boger bedanke ich mich für ihre geduldige Anleitung der Arbeitsmethoden. Britta Kaltwasser danke ich für ihre zuvorkommende Unterstützung in jeglichen Belangen. Jenny, Mimount, Karo und Carina danke ich für viele schöne, lehrreiche und spaßige Stunden, die wir nicht nur während der Arbeit im Labor, sondern auch nach Feierabend zusammen verbracht haben bzw. verbringen. 


\section{LEBENSLAUF}

Am 26. März 1986 wurde ich, Sophia Susanna Scheumann, als Tochter von Dr. med. Gert Scheumann und Maria Scheumann, geb. Tietjen, in Bühl geboren.

Von 1992 bis 1996 besuchte ich die Grundschule in Neuweier und ab 1996 das humanistische Gymnasium „Hohenbaden“ in Baden-Baden. Das 11. Schuljahr verbrachte ich an der „Lincoln School“ in Providence, Rhode Island, in den USA. Zurück in Baden-Baden, erlangte ich meine allgemeine Hochschulreife im Juni 2005.

Zum Wintersemester 2005/2006 begann ich das Studium der Humanmedizin an der GeorgAugust-Universität zu Göttingen. Im Frühjahr 2008 legte ich den Ersten Abschnitt der Ärztlichen Prüfung ab. Zum jetzigen Zeitpunkt bin ich für das Wintersemester 2009/2010 immatrikuliert und werde voraussichtlich 2011 den Zweiten Teil der Ärztlichen Prüfung absolvieren. 